\title{
EL ARTE RUPESTRE PALEOLÍTICO DE LA CUEVA DE AMBROSIO (VÉLEZ-BLANCO, ALMERÍA, ESPAÑA). UNA VISIÓN VEINTE AÑOS DESPUÉS
}

\section{The Rock Art of La Cueva de Ambrosio (Vélez-Blanco, Almería, Spain). A twenty years later view}

\author{
Sergio Ripoll López ${ }^{1}$, Francisco J. Muñoz Ibáñez ${ }^{1}$, Jesús F. Jordá Pardo ${ }^{1}$ \\ e Ignacio Martín Lerma ${ }^{2}$
}

Recibido el 4 de julio de 2013. Aceptado el 17 de julio de 2013

Resumen. Durante las campañas de 1992 y 1994 se encontraron en el yacimiento solutrense de La Cueva de Ambrosio (Vélez-Blanco, Almería, España) un conjunto de representaciones artísticas parietales pintadas y grabadas del Paleolítico superior. Entre los grabados del panel l, se ha descifrado una excelente silueta de caballo, una representación de ave, unos protomos de bóvido y de caballo, así como otros trazos todavía no interpretados. En la parte inferior del panel existen pinturas, poco visibles a causa de una colada calcítica y de momento no es posible interpretar ninguna representación figurativa. En el panel Il se han identificado un total de 25 figuras tanto grabadas como pintadas. La excepcionalidad del hallazgo reside en el hecho de poder interrelacionar perfectamente estas muestras de arte con los niveles arqueológicos claramente definidos desde el punto de vista cultural y cronoestratigráfico (ca. 20000 BP) Solutrense medio y Solutrense superior del mismo yacimiento.

Palabras clave: arte rupestre, Solutrense, cronología, dataciones radiocarbónicas, sureste español.

Abstract. In the solutrean site of La Cueva de Ambrosio (Vélez-Blanco, Almería, Spain) several engraved and painted figures dated on the Upper Palaeolithic, have been found during the field works of 1992 and 1994. In The panel I we have identified an excellent representation of a horse, a bird, one bovidae and another protome of a horse. Below this surface there are many red ochre wall paintings covered by a calcitic speleotheme and for the time being we are unable to give any interpretation for it. In the second panel we have discovered more tone splendid red painted horse, two more enngraved horses and a little head of one other black painted horse. There are many engraved lines and pictural rests that must be studied in the future. The exceptionality of this discovery is that we can interrelate perfectly these rock art paintings with the archaeological levels clearly defined chronologically and culturally (ca. 20000 BP), Middle Solutrean and Upper Solutrean from the same site.

Keywords: rock art, Solutrean, chronology, radiocarbon dates, Southeast of Spain.

(') Departamento de Prehistoria y Arqueologia. Facultad de Geografía e Historia. Universidad Nacional de Educación a Distancia. Ciudad Universitaria.Paseo Senda del Rey 7. E-28040 Madrid (España).sripoll@geo.uned.es·fmunoz@geo.uned.es·jjorda@geo.uned.es.

(2) Departamento de Prehistoria, Arqueología, Historia Antigua, Historia Medieval y Ciencias y Técnicas Historiográficas. Facultad de Letras. Universidad de Murcia. Campus de la Merced Calle Santo Cristo 1. E-30001 Murcia (España). 


\section{INTRODUCCIÓN}

Hace algo más de veinte años, hallamos las primeras figuras solutrenses en La Cueva de Ambrosio (Vélez-Blanco, Almeria, España) (Fig. 1). Durante estos largos años hemos pasado innumerables horas frente a los distintos paneles y otras tantas delante del monitor del ordenador para intentar descifrar aquellos trazos inconexos que observábamos y que no conseguiamos definir. El avance de la tecnología informática, la reflexión y maduración de algunas ideas que ya barajábamos hace un tiempo, nos han permitido engrosar sensiblemente el corpus iconográfico de esta sorprendente estación (Fig. 2).

En esta estación, en la que llevamos trabajando desde hace algo más de 30 años, se ha encontrado una de las secuencias más completas e interesantes para el periodo Solutrense del Mediterráneo español. Según las investigaciones llevadas a cabo hasta ahora, parece que este abrigo no se trataria de un lugar de habitación permanente, sino más bien de un lugar al que se acudia en determinados momentos a renovar el utillaje lítico (Ripoll López et al. 1988) y donde a pesar de la brevedad de sus estancias, constatado a través de la escasa potencia pero gran extensión de los hogares y la poca fauna susceptible de haber constituido un alimento, tuvieron tiempo para plasmar en sus paredes unas muestras de arte rupestre parietal paleolítico.

Hasta el hallazgo del arte rupestre, la única representación figurativa que habíamos encontrado se localizaba sobre un compresor-retocador de caliza, de pequeño tamaño, con un protomos de caballo. Este hallazgo ya fue publicado en su momento (Cacho y Ripoll López 1987; Ripoll López y Cacho 1990) y el encuadre cultural se vio dificultado por la circunstancia de haber sido hallado en el sedimento revuelto durante la campaña de excavaciones del año 1983. Sin embargo, sus características estilísticas nos permitieron incluirlo en un momento evolucionado del Solutrense, perfectamente documentado, por otra parte, en el nivel II del actual relleno del abrigo, aunque hoy pensamos que debería de ser un Solutrense superior.

En La Cueva de Ambrosio el punto "0" de referencia o plano horizontal del yacimiento a partir del cual se miden todas la profundidades se encuentra situado sobre una zona más o menos lisa de la pared izquierda del abrigo. Por otra parte, teníamos noticias de que en este área quedaba algún resto de los niveles epipaleolíticos que por el

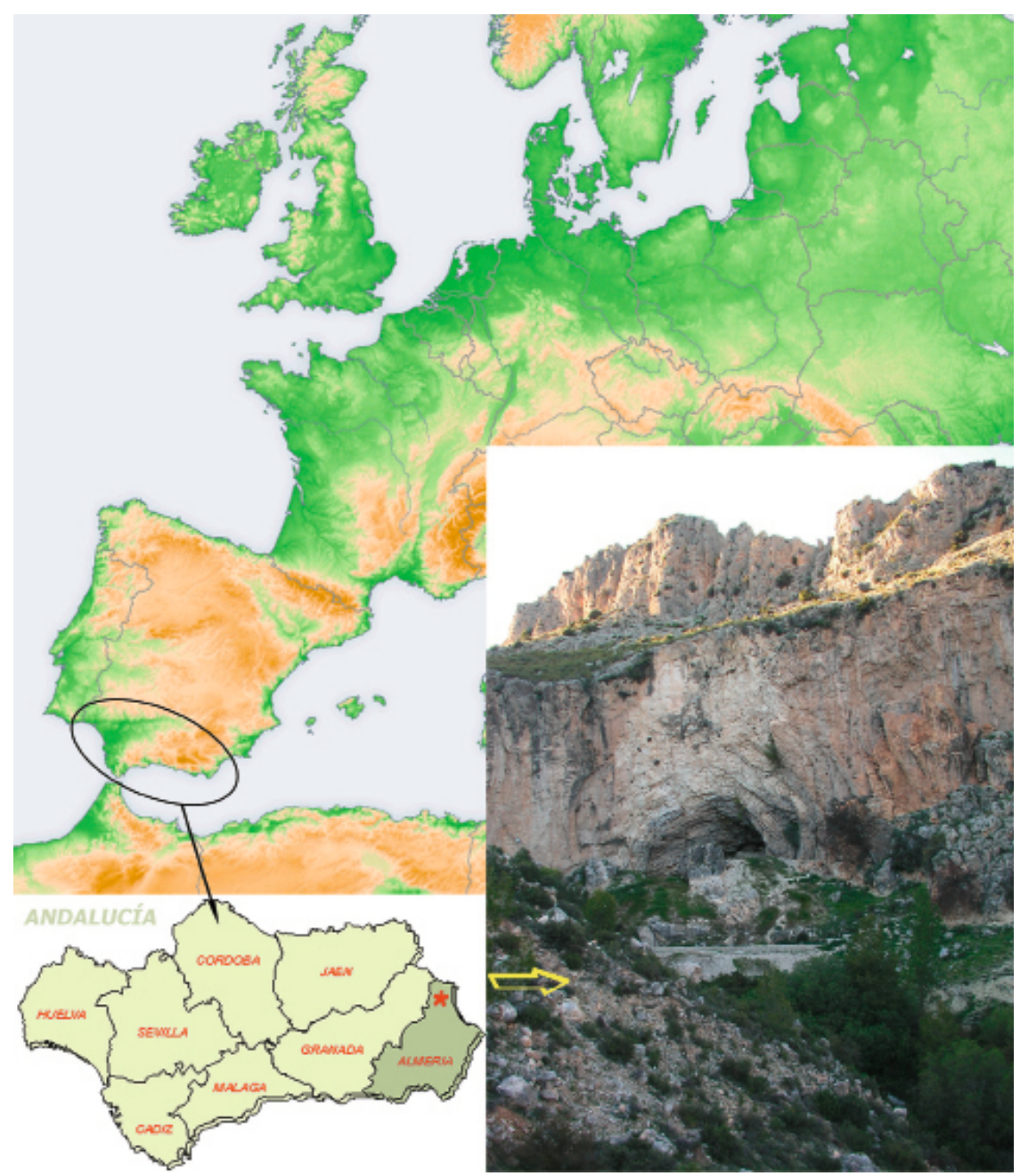

Figura 1. Mapa de situación y vista general de abrigo de La Cueva de Ambrosio. 


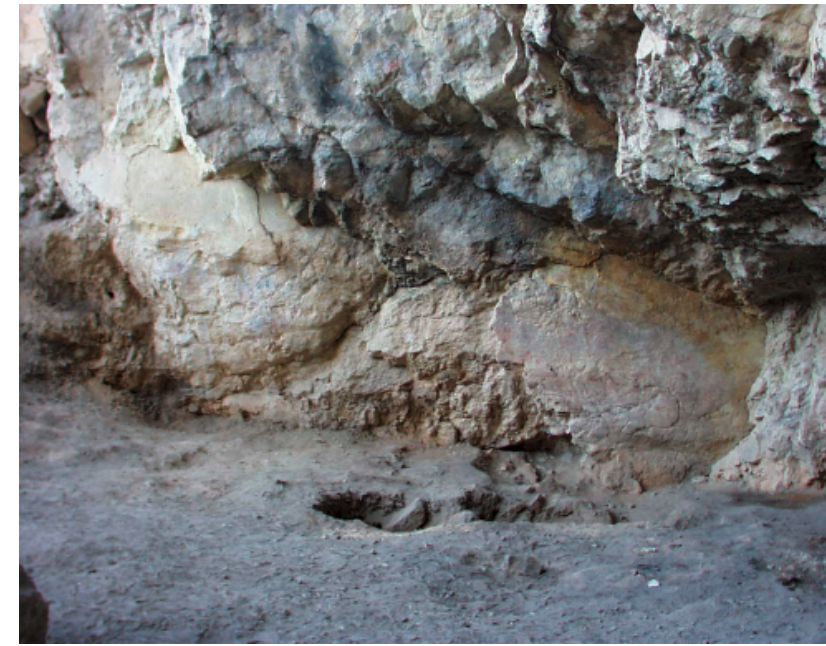

$\Delta$ FIgURA 2. El proyecto de musealización ha supuesto la recuperación de toda la parte oeste del yacimiento, lugar en el que se ubican los paneles decorados. A la izquierda el panel I y a la derecha los paneles II y III.

momento no pensábamos investigar, preservándolos como reserva arqueológica. La superficie, a la que antes aludiamos, se sitúa a la derecha y por debajo de aquellos estratos y conservaba adheridos abundantes restos de sedimento de color amarillento que siempre habiamos encuadrado en el nivel estéril que separa los niveles superiores del Solutrense y los del Epipaleolítico. Además, al tratarse del umbral del abrigo, en algunas zonas se había depositado algún material de arrastre y una parte había cubierto la marca del punto "0", dificultando su visión, motivo por el que decidimos limpiarlo.

Al limpiar esta zona de la pared del abrigo, nos dimos cuenta de la idoneidad de la misma para contener representaciones incisas y continuamos esta tarea sin demasiadas esperanzas ya que habian sido numerosos los investigadores que nos precedieron en el estudio de esta estación y no habian constatado representaciones parietales de ningún período. Pero para nuestra sorpresa, nos dimos cuenta de la existencia de algunas líneas grabadas que se extendian hacia el interior del abrigo. Finalmente, comprobamos que se trataba de un équido (Fig. 3) y de un ave.

Este descubrimiento nos llevó a realizar una exhaustiva revisión de todas las paredes de la estación, con el fin de determinar si existían más representaciones. De esta forma en la parte inferior del panel grabado localizado en primer lugar, hallamos abundantes restos pictóricos y más hacia el interior del abrigo, al limpiar otra zona que contenía numerosas líneas incisas, también encontramos algunas figuras pintadas.

Las manifestaciones de arte rupestre se concentran en tres paneles. El panel I se sitúa en el área exterior de la pared izquierda del abrigo; en la misma pared, a unos 4,50 metros del anterior, hacia el fondo de la cavidad y en una posición claramente inferior se encuentran los paneles II y III.

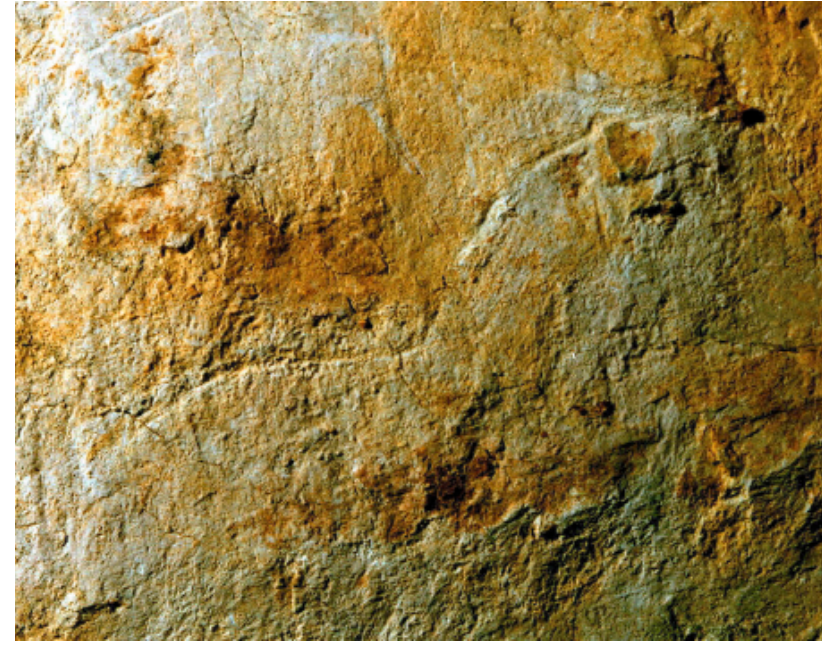

\ Figura 3. Esta figura de caballo incisa profundamente en la caliza del panel IA, fue la primera representación identificada en La Cueva de Ambrosio.

Todas las representaciones localizadas hasta el momento fueron realizadas sobre una superficie rocosa, más o menos lisa, limpia o ligeramente concrecionada de color blanquecino o beige (10YR 8/1). La mayor parte de la colada calcítica que recubre la parte inferior del panel I se debe a una fase húmeda, claramente posterior a su ejecución.

\section{DESCRIPCION DE LAS FIGURAS}

\subsection{Panel I}

En el panel I (Fig. 4) hemos distinguido a su vez la parte superior y la inferior. En la de arriba, caracterizada por encontrarse exclusivamente representaciones incisas, hemos identificado un total de cinco figuras. Procederemos a describirlas de izquierda a derecha, en el sentido de las agujas del reloj, haciendo referencia a su color según las tablas Munsell (Munsell 1954). Las figuras son las siguientes:

1. En primer lugar se aprecia una figura de ave que mira hacia la derecha con una longitud de $30,4 \mathrm{~cm}$ por 18,1 cm de anchura, una máxima entre paralelas de $29 \mathrm{~cm}$. La orientación es de $250^{\circ}$ y el buzamiento de $70^{\circ}$. Esta figura está realizada mediante un surco de 2-3 mm de anchura y tiene una profundidad que oscila entre los $2 \mathrm{~mm}$ de la parte posterior y $0,05 \mathrm{~mm}$ del pico. El cuerpo es fusiforme, bien diferenciado y un pico puntiagudo que se prolonga a partir de la cabeza redondeada. La zona ventral está bastante perdida y no se aprecian las patas que podrían proporcionarnos una identificación zootécnica más precisa. Por el tipo de pico podría tratarse de una anátida, pero por otra parte la silueta, en 
general, recuerda a una perdiz, especie de la que hemos encontrado restos en los niveles de ocupación (Sánchez Marco 1988), y que sin duda integró la dieta alimenticia de estos grupos del Paleolítico superior final.

2. En este mismo panel I, hacia la derecha y a escasos centímetros de la anterior, se encuentra la primera figura incisa que descubrimos en La Cueva de Ambrosio. Se trata de una espléndida figura de équido orientada hacia la derecha de $29 \mathrm{~cm}$ de longitud por $16,2 \mathrm{~cm}$ de anchura, una máxima entre paralelas de $29 \mathrm{~cm}$, una orientación de $252^{\circ}$ y un buzamiento de $70^{\circ}$. La línea cérvico-dorsal está realizada mediante un surco bastante amplio (2-3 $\mathrm{mm}$ ) y profundo, de sección en $U$, frente al despiece de la crinera, cuyos trazos son muy finos y someros, sin poder llegar a medir su profundidad. La incisión de la quijada es casi inexistente observándose, sin embargo, algunas estrías que permiten completar la figura junto con los resaltes naturales de la roca. La línea cérvico-dorsal forma casi un ángulo recto. Esta última línea se prolonga desde la grupa hasta la crinera, donde se desdobla en un haz de trazos más finos, representando el despiece de la misma y tal vez el pelaje. La cabeza, de forma subcuadrangular, ligeramente inclinada hacia arriba, está realizada aprovechando un resalte natural de la roca base. La oreja está confeccionada mediante un simple ángulo en la parte superior y la línea de la cara se desarrolla hasta el morro, a partir de donde se aprovecha en mayor medida el resalte, incidiendo únicamente con un trazo más somero, en la parte del belfo que adquiere la característica convención en forma de "pico de pato". A continuación se perfila la quijada

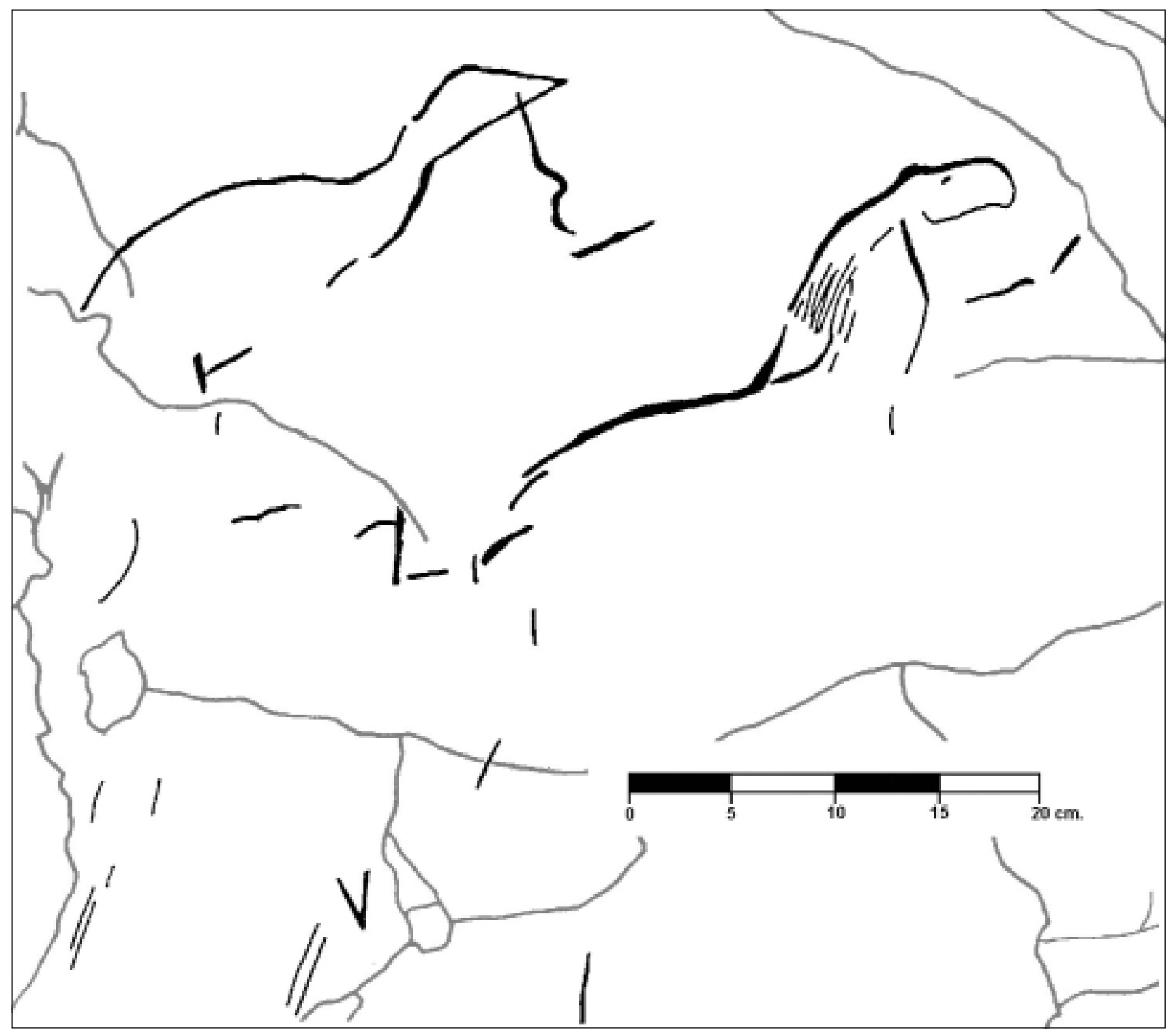

$\Delta$ Figura 4. Calco de la parte superior del panel I con las representaciones incisas de ave y équido descritas en el texto. 
que asciende ligeramente hacia el interior de la cabeza en su parte final. En la zona interior de la testuz se distingue con bastante claridad lo que hemos identificado como el ojo, realizado mediante un impacto martilleado circular. Escasamente relacionada con el resto de la figura se diferencia la línea del pecho. Parece que de forma intencional no se ha querido representar la parte inferior del cuerpo, es decir las extremidades y la línea ventral. Se trata de un animal con unas proporciones equilibradas en el que se pone de manifiesto su acusado realismo, aunque no está exento de tendencias estilizadas. El contorno de esta representación muestra un équido asustado o alarmado con la parte anterior de su cuerpo en posición erguida como para distinguir la causa que lo ha alertado, ya fuera sonido u olor.

3. En la parte inferior derecha de este panel I hemos distinguido otras figuras. En primer lugar hay que señalar una línea cérvico-dorsal y la oreja de un équido que mira hacia la derecha con $17,5 \mathrm{~cm}$ de longitud y $10,4 \mathrm{~cm}$ de anchura, con una orientación de $246^{\circ}$ y un buzamiento de $83^{\circ}$. El trazo es ancho y profundo, alcanzando los $2 \mathrm{~mm}$ de espesor y $1 \mathrm{~mm}$ de profundidad y de sección en $U$, pero al encontrarse sobre una pequeña inflexión de la roca, que cambia de dirección, no se ha conservado el resto de la figuración.

4. También bastante incompleto, pero más identificable, es un protomos de bóvido orientado hacia la izquierda cuyas medidas apenas alcanzan los $5,8 \mathrm{~cm}$ de longitud por $3,5 \mathrm{~cm}$ de anchura, con una orientación de $245^{\circ}$ y un buzamiento de $80^{\circ}$. El trazo es bastante profundo y amplio en todo el contorno ( $2 \mathrm{~mm}$ ) con una sección en $U$, salvo en el cuerno que es más tenue y de sección en $\mathrm{V}$. Se diferencia bien el cuerno curvado hacia atrás, en perspectiva simple y la cabeza ligeramente subtriangular, y a continuación el inicio de la línea dorsal, así como la del pecho. Existen otros grabados de las mismas caracteristicas por toda esta extensa superficie, pero de momento, a falta de un análisis más pormenorizado, no hemos conseguido identificar otras representaciones naturalistas. Además se adivinan otras líneas sumamente someras -como si hubiesen sido raspadas- sobre esta misma superficie que tendremos que investigar en futuras campañas de documentación.

\subsection{Panel I-B}

Uno de los aspectos principales en los ensayos realizados ha sido el método de obtención de imágenes con un contenido informativo diferente, mediante una selección espectral. Para ello decidimos, en principio, trabajar con aquellos productos fotográficos disponibles en el mercado y observar los resultados que pudieran proporcionar combinando el máximo de opciones posibles. De esta manera recurrimos al uso de películas en blanco y negro, color e infrarroja con ayuda de filtros adecuados a cada una de ellas. Es imprescindible tener en cuenta las caracteristicas de sensibilidad de las películas y de los filtros elegidos para limitar la radiación recogida para conocer el rango del espectro electromagnético registrado en cada una de las imágenes.

En la parte inferior del panel I-A, distante unos $40 \mathrm{~cm}$ del superior, por debajo de la inflexión antes mencionada, hemos hallado unos restos pictóricos en ocre rojo muy desvaído (10R 3/6). Todos ellos se localizan por debajo de una colada calcítica de espesor variable y muy desescamada, que los hace poco visibles. Las figuras son las siguientes:

1. En el extremo izquierdo del panel, junto al sedimento intacto, se aprecia una silueta eliptica que hemos asociado a una cabeza de caballo dispuesta hacia la izquierda con unas dimensiones de $28 \mathrm{~cm}$ de longitud y $13 \mathrm{~cm}$ de anchura, con una orientación de $276^{\circ}$ y un buzamiento de $74^{\circ}$, pintada en ocre rojo (10R-4/8) y en la que también se distingue parte de la línea cérvico-dorsal.

2. Más hacia la derecha hemos concretado otra línea horizontal que se identifica con la zona cérvicodorsal de un cuadrúpedo, posiblemente un équido. Esta dispuesto hacia la izquierda y tiene una longitud de $31 \mathrm{~cm}$ por $4 \mathrm{~cm}$ de anchura, con una orientación de $276^{\circ}$ y un buzamiento de $74^{\circ}$, pintado en color ocre rojo oscuro (10R-3/3).

3. Hay otros trazos inconexos entre los que se distingue una silueta subcuadrangular con una longitud de $66 \mathrm{~cm}$ y una anchura de $33 \mathrm{~cm}$ con una máxima entre paralelas de $66 \mathrm{~cm}$. La orientación es de $275^{\circ}$ y el buzamiento de $70^{\circ}$. Está pintado en un color ocre rojo (10R 4/8) que tal vez podría clasificarse como un típico signo paleolítico (¿tectiforme?). Más hacia la derecha, y en una posición sensiblemente inferior, existe otro trazo también en ocre anaranjado (2.5YR 4/8), bastante evidente que podría corresponder a los cuartos traseros e inicio de la línea ventral de un cuadrúpedo. Sin duda su limpieza exhaustiva en un futuro nos proporcionará un amplio repertorio de figuras que engrosarán el inventario de este inusual descubrimiento.

\subsection{Panel II}

El segundo panel (Figs. 5 a 14), situado más hacia el interior del abrigo, se encontraba oculto por una espesa 
capa de sedimento revuelto y bloques procedentes de excavaciones incontroladas. Empezamos a retirarla con mucha precaución, ya que se adivinaba una gran superficie lisa e inmediatamente distinguimos un conjunto de trazos grabados de enorme complejidad, así como dos pequeñas manchas de ocre rojo en la parte inferior.

La superficie del panel II es mucho más regular, de un color gris - marrón (7.5YR 6/4), en todo caso más oscura que la del panel I. Está surcada por finas grietas que no restan uniformidad al conjunto de figuras. En el momento de su descubrimiento aparecieron pequeñas escamas de concreción caliza, sobre todo en la zona ocupada por el équido grabado (n. $\left.{ }^{\circ} 13\right)$.

De una manera totalmente accidental, tuvo lugar el descubrimiento de la figura más espectacular de toda la campaña: un espléndido caballo pintado en color ocre rojo, en una zona en la que ya habíamos empezado a trabajar. Sorprende por su buen estado de conservación general y sobre todo contrasta con las otras figuras descritas en el panel I por su claridad y notables dimensiones.

1. Pequeña cabeza de caballo dispuesta hacia la izquierda con unas dimensiones de $7 \mathrm{~cm}$ de longitud y $5,5 \mathrm{~cm}$ de anchura con una orientación de $254^{\circ}$ y un buzamiento de $72^{\circ}$. El grabado es de sección en $V$ con una anchura y profundidad inferiores a $1 \mathrm{~mm}$. Está situada en la parte superior izquierda del panel, zona de color rojizo, no por el soporte, sino por contener abundantes restos de ocre rojo (2.5YR $6 / 6)$. La quijada, al igual que la crinera, termina en sendos desconchones de la roca soporte. Se distingue claramente una de las orejas, enhiesta y carece de otros detalles anatómicos.

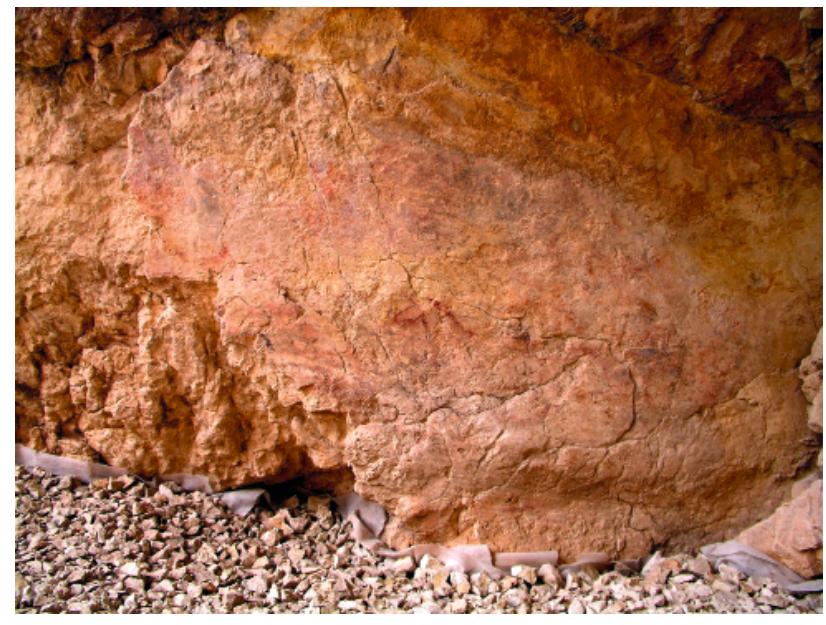

A Figura 5. Vista de conjunto del panel II, situado más hacia el interior de la cavidad. En esta superficie hemos identificado un total de 8 figuras atribuibles al Solutrense Medio. La acumulación de cantos, corresponde prácticamente con el nivel de ocupación desde el cual se pintaron y grabaron estas manifestaciones artísticas.
2. También en el ángulo superior izquierdo, después de haber retirado una considerable extensión de costra calcítica, hemos hallado una pequeña cabeza de caballo con unas medidas que apenas alcanzan los 6,3 cm de longitud por 7,6 de anchura, con una orientación de $254^{\circ}$ y un buzamiento de $72^{\circ}$, orientada hacia la izquierda, realizada mediante un trazo sumamente fino y somero (inferiores a $1 \mathrm{~mm}$ ). A pesar de las reducidas dimensiones se distingue una ligera inflexión en el belfo que no llega a adquirir la característica convención del pico de pato, y una de las orejas que aparece enhiesta.

3. Cabeza de cuadrúpedo orientada hacia la izquierda con unas dimensiones de $17 \mathrm{~cm}$ de longitud y 15 $\mathrm{cm}$ de anchura con una orientación de $265^{\circ}$ y un buzamiento de $76^{\circ}$. El grabado es muy somero y poco profundo de sección en $\mathrm{V}$. Esta figura está situada a la izquierda y abajo de las anteriores. Posiblemente se trate de un équido ya que tiene la oreja enhiesta, la boca abierta y se insinúa el inicio del cuello. Destaca en el interior un gran ojo circular que a pesar de su morfología está bien situado anatómicamente.

4. En el interior de la figura $n .^{\circ} 3$ hallamos esta otra pequeña cabeza de cuadrúpedo también orientada hacia la izquierda con 6,5 cm de longitud y $9,5 \mathrm{~cm}$ de anchura (desde las orejas hasta la quijada) con una orientación de $265^{\circ}$ y un buzamiento de $76^{\circ}$. El grabado es mucho más amplio, en comparación con el resto de representaciones de caballos, con una sección en $U$ y una anchura de $4 \mathrm{~mm}$ y una profundidad de apenas $1 \mathrm{~mm}$. Las dos orejas situadas en la parte superior de la cabeza en una

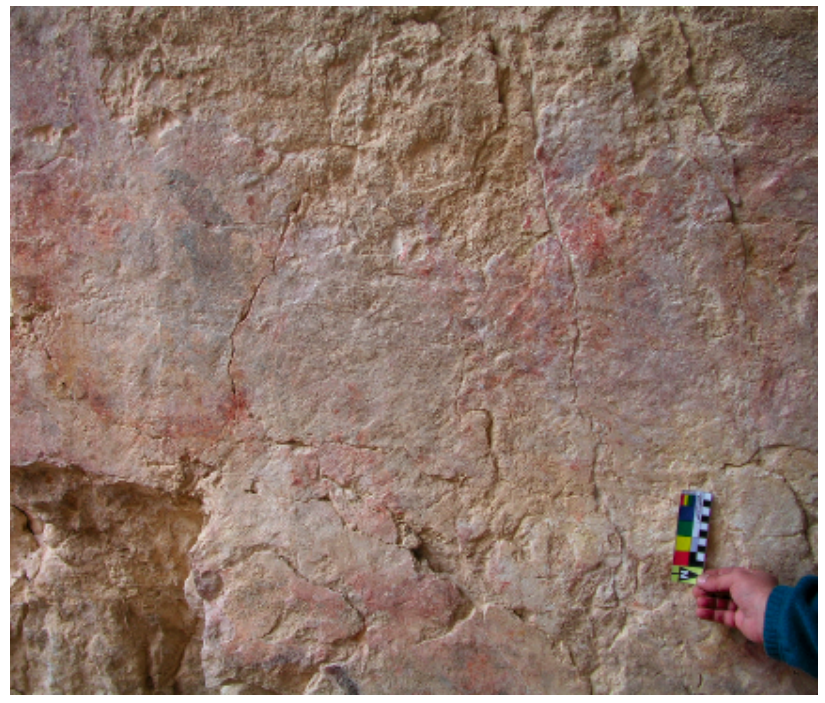

$\Delta$ Figura 6. Detalle de la zona izquierda el panel II donde se aprecian una serie de figuras incisas entre las que destaca la gran cabeza de cáprido orientada hacia la derecha. 


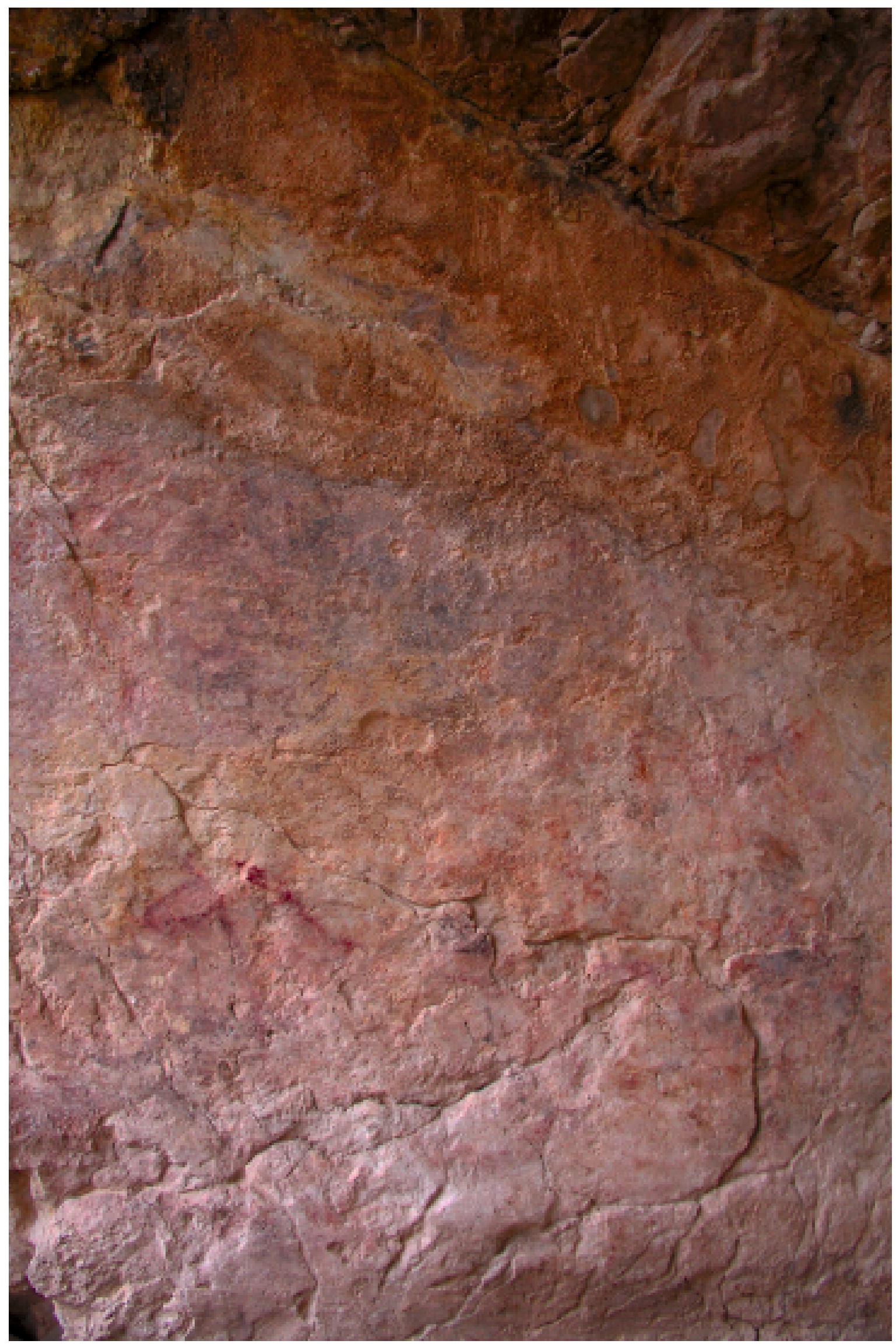

ム Figura 9. Vista de la zona central del Panel II donde se localizan diversas figuras entre las que destaca el magnífico caballo pintado en ocre rojo. 


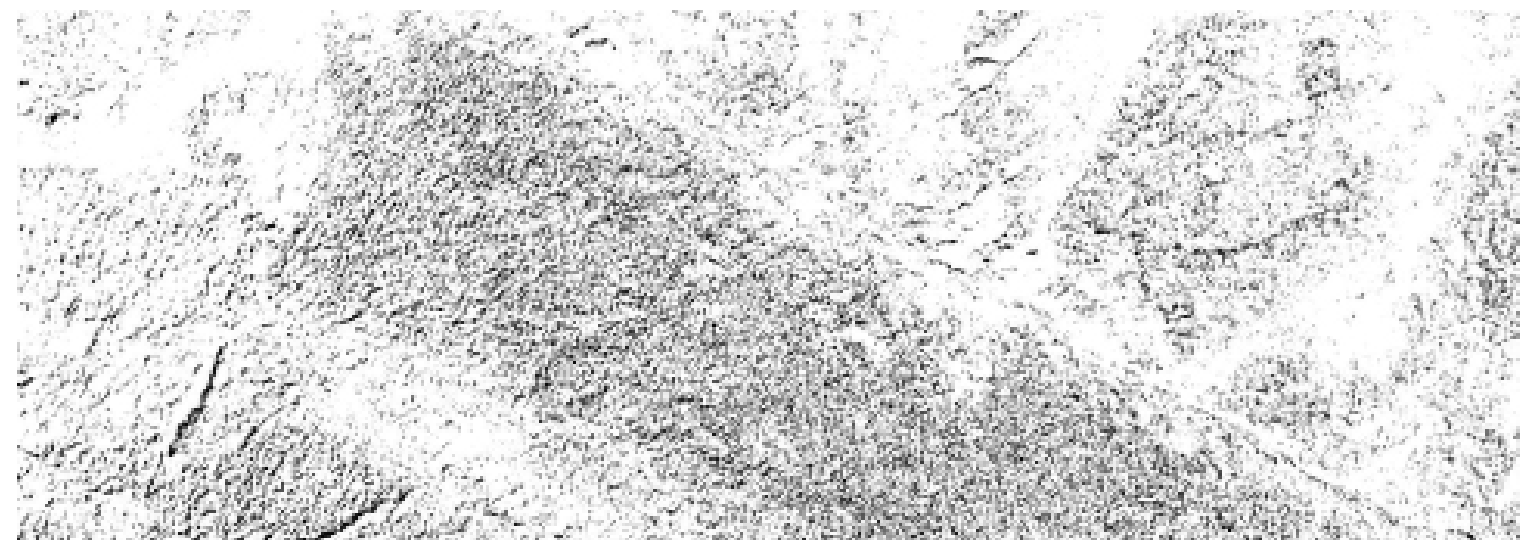

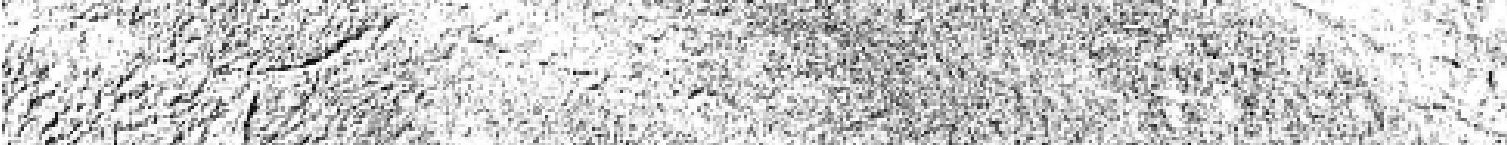

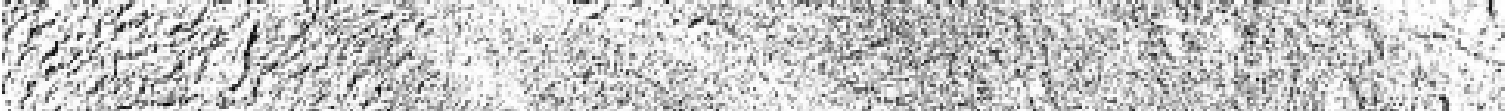

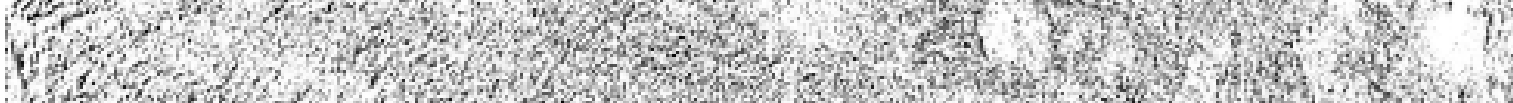

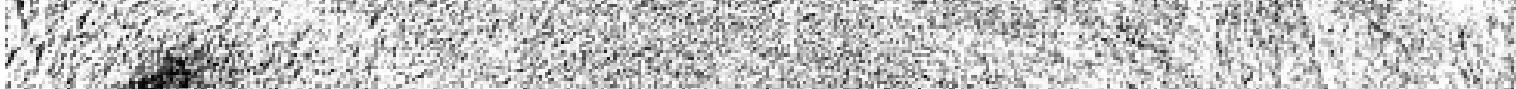

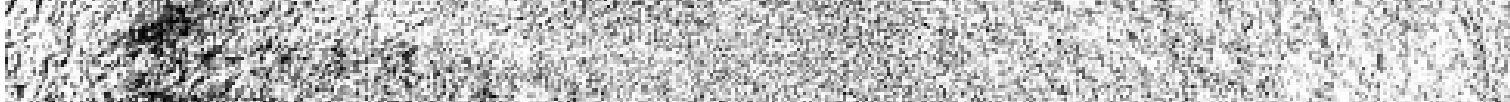

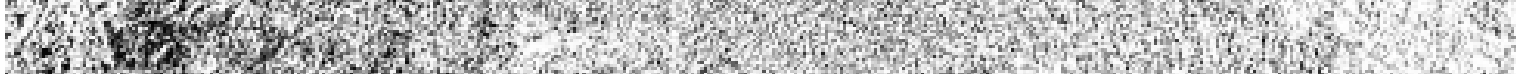

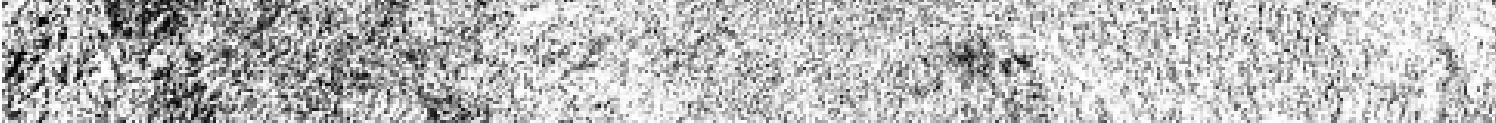

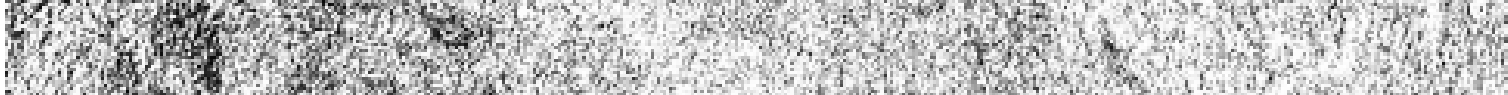

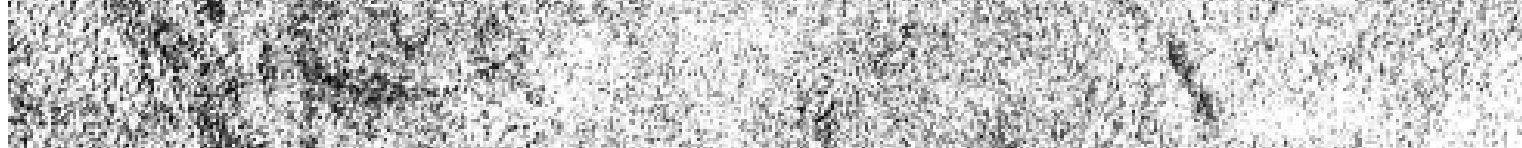

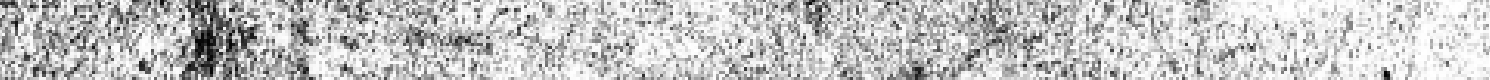

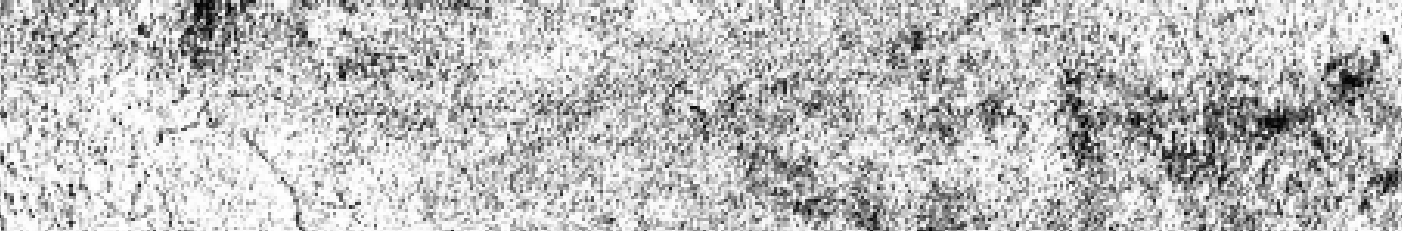
W.

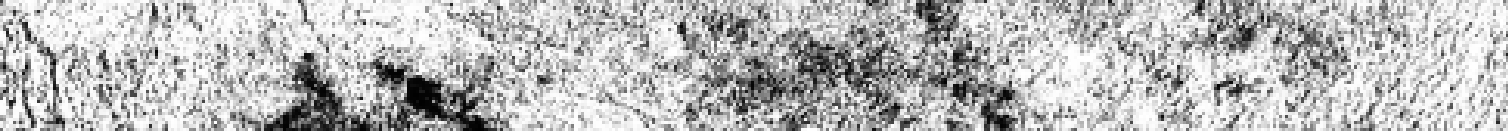

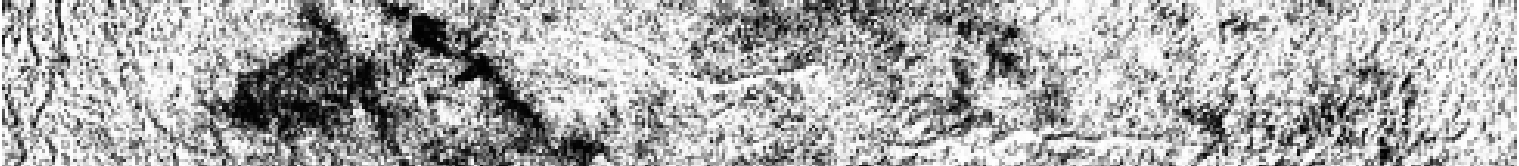

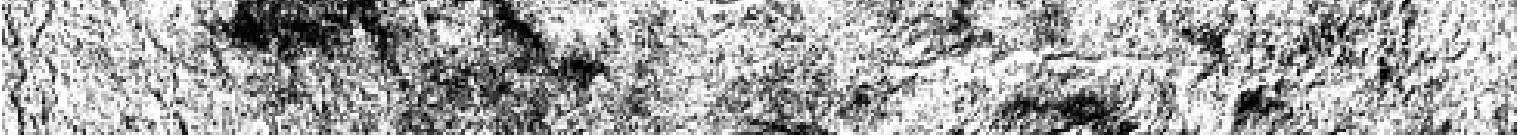

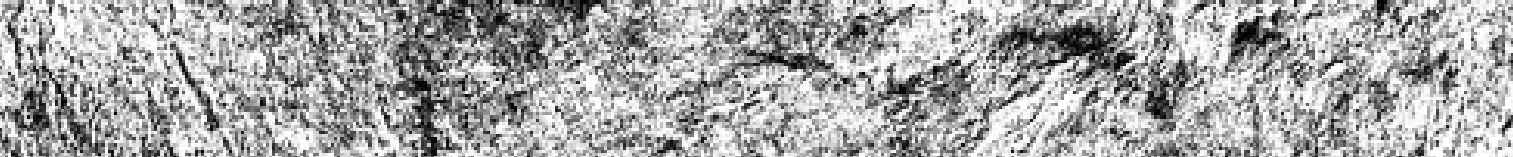

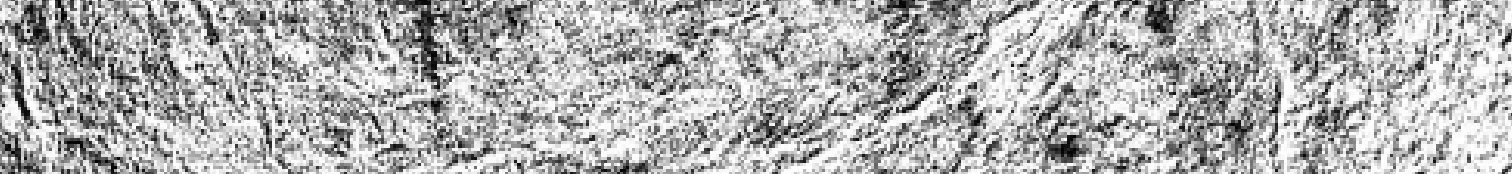

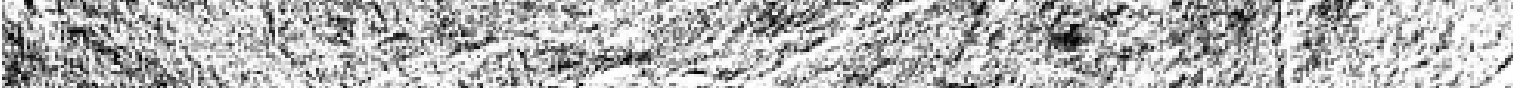

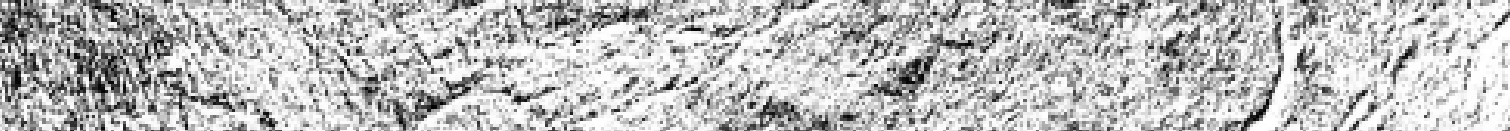

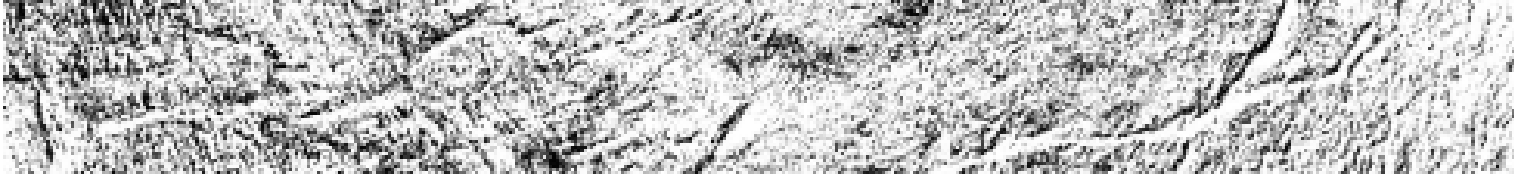

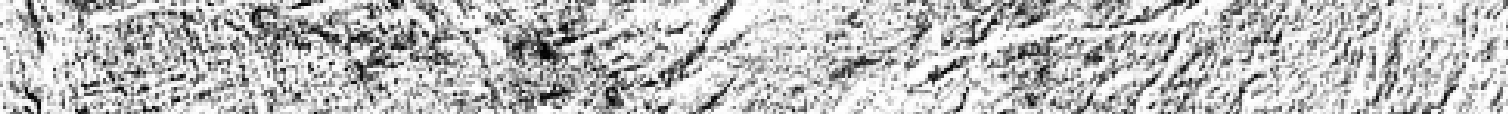

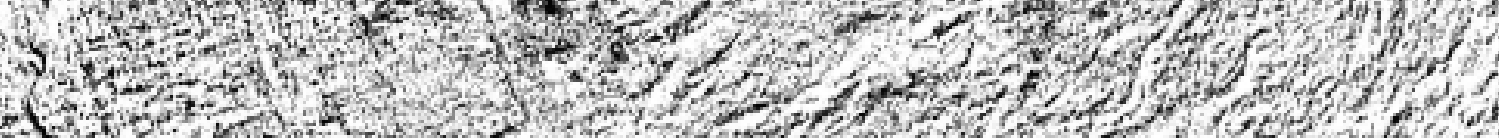

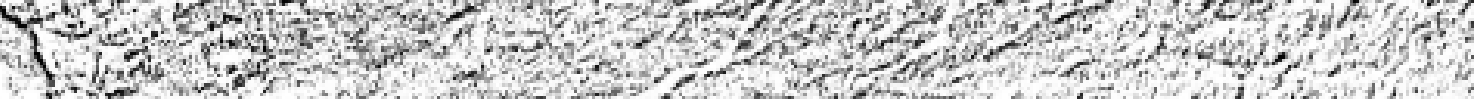

A FiguRa 10. El tratamiento digital (ocres) realizado por Vicente Bayarri de la empresa Gim-Geomatics no ha permitido definir con mayor precisión las diferentes partes anatómicas del caballo rojo. 


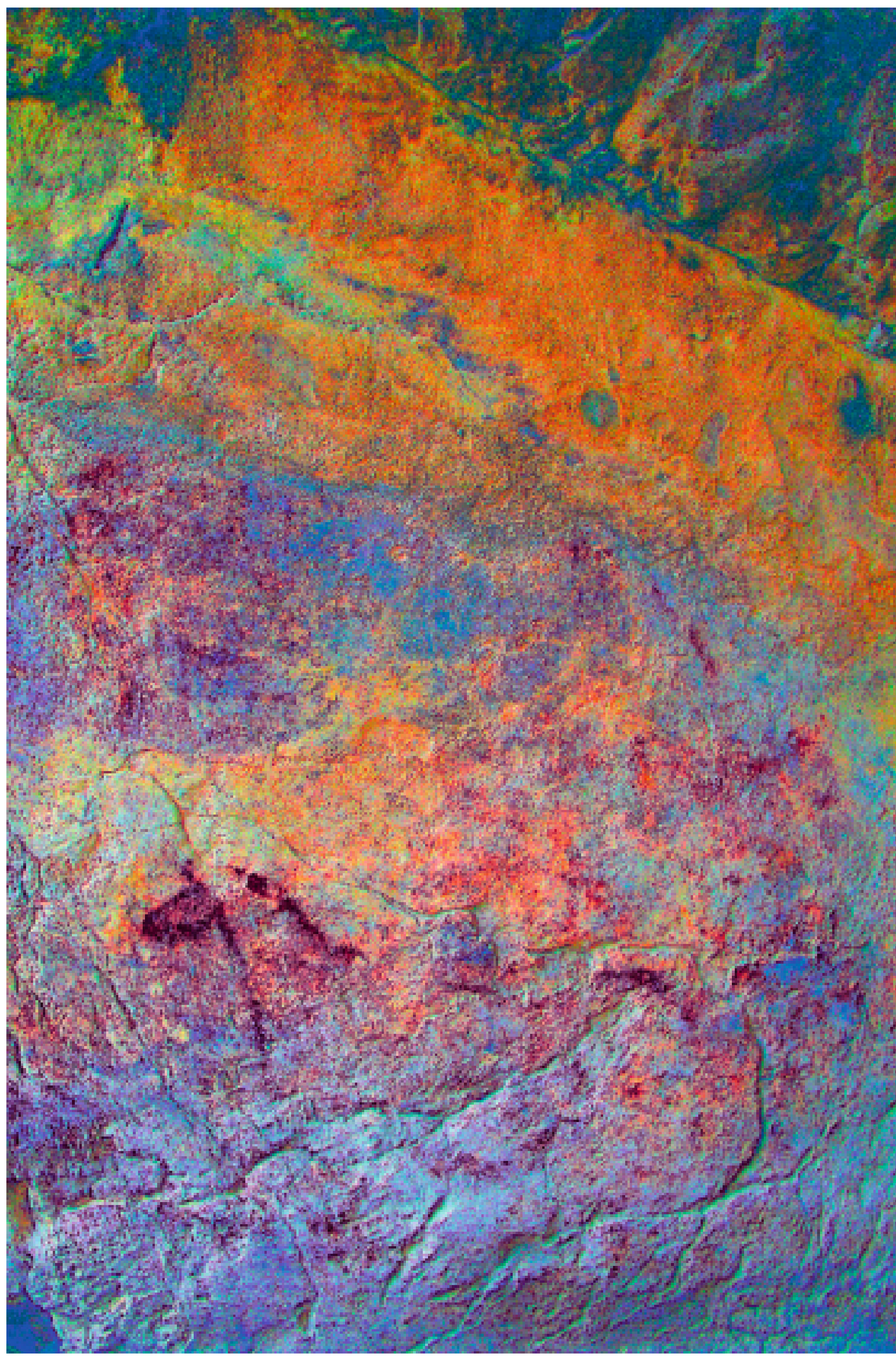

ム Figura 11. El tratamiento FIR de la imagen 9 nos permite descubrir el vientre y el inicio de las manos y patas del caballo rojo. 


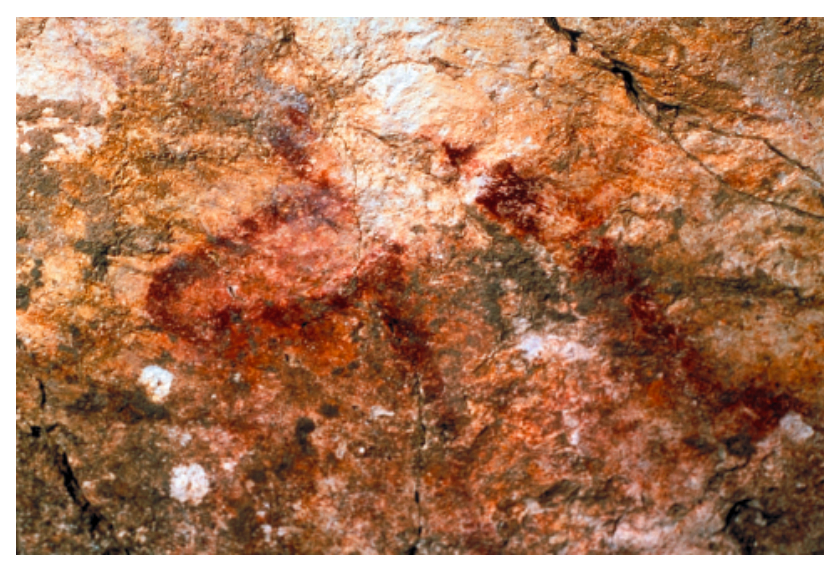

ム Figura 12. Protomos del caballo pintado en ocre rojo número 8, situado en el centro del panel II. El resto de las representaciones se sitúan a su alrededor.

perspectiva torcida, están realizadas con un surco de sección en $\mathrm{V}$ muy somero. Carece de detalles anatómicos específicos, salvo una quijada bastante pronunciada y un ojo circular acorde con el resto de la figura.

5. Más hacia la derecha, a la misma altura que las anteriores, se distinguen otras dos figuras que están superpuestas. La primera de ellas es una cabeza de cuadrúpedo orientada hacia la izquierda con $13 \mathrm{~cm}$ de longitud y $8,5 \mathrm{~cm}$ de anchura con una orientación de $262^{\circ}$ y una buzamiento de $75^{\circ}$. El grabado es de sección en $U$ con una anchura de $2 \mathrm{~mm}$ y una profundidad inferior a $1 \mathrm{~mm}$. Parece que se puede tratar de un caballo ya que sigue las mismas pautas que todos los identificados en el panel II. La parte superior, correspondiente a las orejas, está ausente por un desconchón de la roca soporte. Se aprecia el inicio del cuello que se pierde en una grieta. En el interior hemos identificado un gran ojo de morfología circular al igual que el resto de figuras.

6. Justo encima de la testuz de la figura $n . .^{\circ} 5$ hallamos otra cabeza de cuadrúpedo dispuesta hacia la izquierda con una reducidas dimensiones que apenas alcanzan los $9 \mathrm{~cm}$ de longitud y $3 \mathrm{~cm}$ de anchura con una orientación de $240^{\circ}$ y un buzamiento de $73^{\circ}$. El surco es de sección en $V$ con escasa profundidad y anchura. Únicamente se distingue la testuz, el inicio del morro y al contrario que las otras figuras, un ojo almendrado. No se aprecian más detalles debido a la mala conservación de la roca soporte.

7. Gran cabeza de caprino orientada hacia la derecha con unas dimensiones de $61 \mathrm{~cm}$ de longitud y 49 $\mathrm{cm}$ de anchura con una orientación de $240^{\circ}$ y un

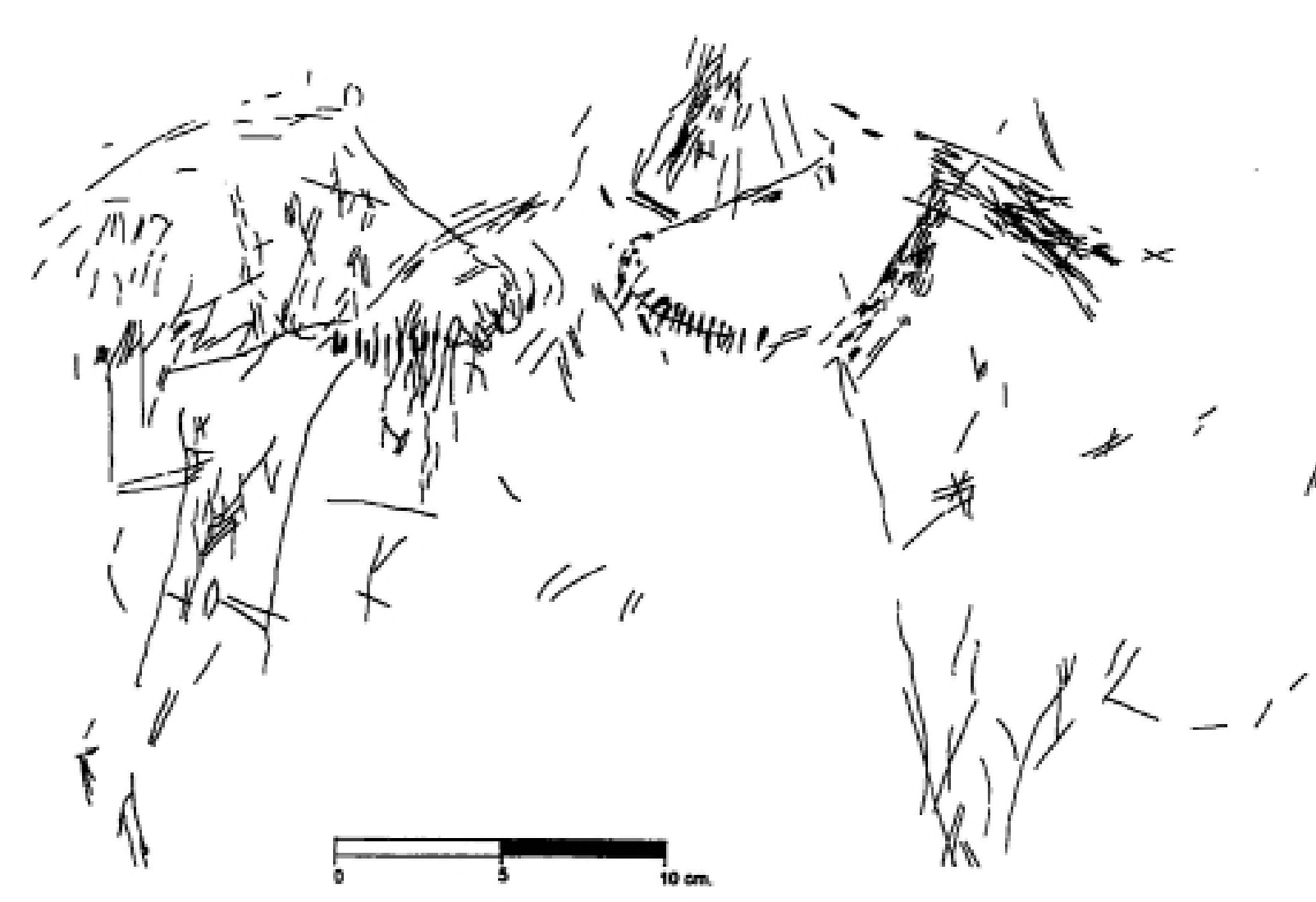

A Figura 13. Calco de los dos caballos grabados enfrentados. 
buzamiento de $76^{\circ}$. El surco de la incisión es de sección en $U$ y la anchura varía entre 1,5 y $1 \mathrm{~mm}$ y la profundidad apenas alcanza $1 \mathrm{~mm}$. Se trata de una figura muy compleja realizada mediante dos técnicas gráficas diferentes que se dispone ligeramente hacia arriba y a la derecha. La oreja y el cuerno curvo están pintados en negro (2.5 YR 0/5) muy desvaído adquiriendo una tonalidad grisácea, mientras que el resto de la cabeza está realizada mediante grabado. A partir del arranque del cuerno, que está caracteristicamente curvado hacia atrás, identificamos la testuz, ligeramente convexa que se prolonga hasta el morro en donde se aprecia la boca abierta, de la que sale un trazo curvo, probablemente la lengua. Esta característica fue estudiada por Sacchi (2008) y se trata de una convención muy habitual entre las representaciones de caprinos machos y que se puede asociar con la época del celo. En el interior de la cabeza se distingue con mucha claridad un gran ojo de forma almendrada y en la zona del morro también hemos identificado el ollar, que tiene una forma arriñonada, que se corresponde así mismo con el ojo de la figura antropomorfa n. 8 que describiremos a continuación. A partir del labio inferior, se distingue la quijada que se prolonga hasta el inicio del cuello. Todo el interior de la cabeza debió de estar relleno de ocre rojo, a modo de tinta plana, que en la actualidad está muy desvaído y lavado ( 2.5 YR 6/6). En la zona correspondiente al cuello de esta cabra, se aprecia una gruesa línea curva de color ocre rojo, que hemos asociado al vientre de otro cuadrúpedo. El análisis de los diferentes tratamientos fotográficos no nos ha permitido definir con mayor exactitud esta representación debido sin duda a los desprendimientos naturales de la roca soporte, existentes en esta zona del panel II. La superficie rocosa sobre la que está representada esta figura es una de las más lisas y apropiadas del panel II, aunque en la zona correspondiente al inicio del cuerpo hubo un gran desprendimiento, que sin duda ha provocado que la representación esté limitada a la cabeza. Probablemente la idoneidad de la superficie fue la elegida por los artistas solutrenses para plasmar una gran cantidad de figuras con numerosas superposiciones ya que en la zona del morro del caprino hemos identificado cinco figuras que se describen a continuación.

8. El 8 de octubre de 2008, durante una visita rutinaria a La Cueva de Ambrosio, para comprobar el estado de conservación de las distintas representaciones halladas en el año 1992, los que suscribimos este texto, realizamos un descubrimiento de gran importancia: la representación de una cara humana (Fig. 7 y 8). Se trata de una representación de una cabeza humana orientada hacia la izquierda con una longitud de $12,8 \mathrm{~cm}$, una anchura de $13 \mathrm{~cm}$ y una máxima entre paralelas de $11 \mathrm{~cm}$. La orientación es de $244^{\circ}$ y el buzamiento de $74^{\circ}$. El grabado está realizado con mano firme, sin rectificaciones y con una anchura y profundidad que no alcanza los $3 \mathrm{~mm}$. El surco es continuo salvo en las dos zonas dónde ha habido desprendimientos de la roca-soporte, es decir en la zona anterior de la cabeza y en la parte de la nuca. En algún punto, como puede ser el área del bigote y la boca, se conserva algún resto de colada calcítica muy fina que no resta continuidad al surco inciso. La representación debió de estar totalmente pintada en tintas planas con ocre rojo, ya que por toda la superficie se conservan restos de este pigmento. Pero es en la zona de la barbilla donde la concentración de colorante es mayor (2.5 YR 6/6), formando un trazo curvo que configura con claridad esta zona anterior del cuello. El agujero izquierdo de la nariz también está realizado mediante un surco más fino y somero que está relleno con un colorante negro muy desvaído (7.5 YR 5/0). Veamos detalladamente su descripción:

\section{El cráneo}

- El occipucio. A pesar de que la parte más evidente del presente retrato es la cara, podemos descubrir en un trazo algo más fino y somero la parte del occipucio que se sitúa a la derecha de la grieta existente. La forma es convexa y en la parte superior tiene un ligero abultamiento provocado sin duda por una breve protuberancia de la roca soporte. La nuca está insinuada por un trazo ubicado a la izquierda de la mencionada grieta. El palimpsesto que forman las distintas figuras superpuestas dificulta el seguimiento de las distintas partes del cráneo, pero al tratarse surcos de desarrollo más o menos vertical, no se pueden confundir con los de los équidos situados en la misma zona.

- El sincipucio. La bóveda craneana es claramente media-alta y con una forma plano-convexa. De cualquier forma esta zona del cráneo se intuye por la extrapolación de la línea de la frente y un trazo aislado en la parte superior.

- La frente, en el caso de La Cueva de Ambrosio el perfil está representado como un perfil exacto en el sentido en que lo entiende la antropología morfológica, es decir que está trazado siguiendo el plano sagital medio. En esta figura la frente es abombada, ligeramente cóncava y en la parte superior tiende 
Sergio Ripoll López, Francisco J. Muñoz lbáñez, Jesús F. Jordá Pardo e Ignacio Martín Lerma

a huidiza. El artista que llevó a cabo este grabado junto al gran caballo rojo, posiblemente idealizó un perfil de una cara que le era conocida, dificilmente la suya propia ya que su reflejo lo presentaría siempre de frente.

\section{La cara}

- Los ojos. En nuestro caso el ojo carece de detalles específicos como puede ser la ceja, el párpado o la pupila. Simplemente está sugerido y adopta una

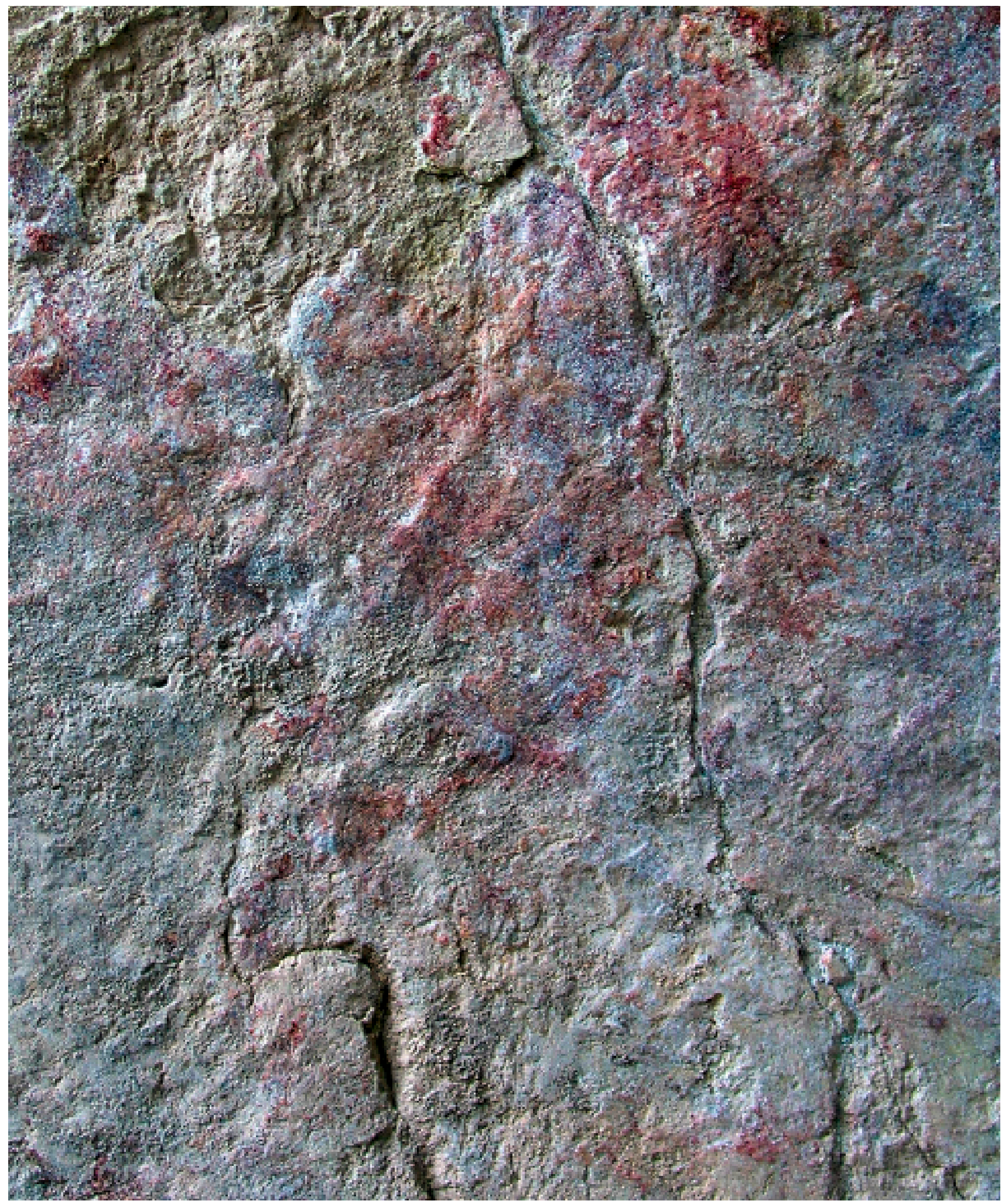

A Figura 7. Detalle des retrato humano identificado en la zona izquierda del panel II. 
forma arriñonada vertical que mide $2,3 \mathrm{~cm}$ en la parte más alargada, mientras que la parte más estrecha alcanza 2,1 cm. Se da la circunstancia que el ojo de este retrato coincide con el ollar de la gran cabeza de cabra que está infrapuesta. No nos vamos a extender en las posibles morfologías de los ojos ya que el texto se alargaría innecesariamente.

- La nariz. El retrato de La Cueva de Ambrosio posee una nariz ligeramente respingona, pudiéndose considerar incluso casi recta. La escotadura nasal o na-

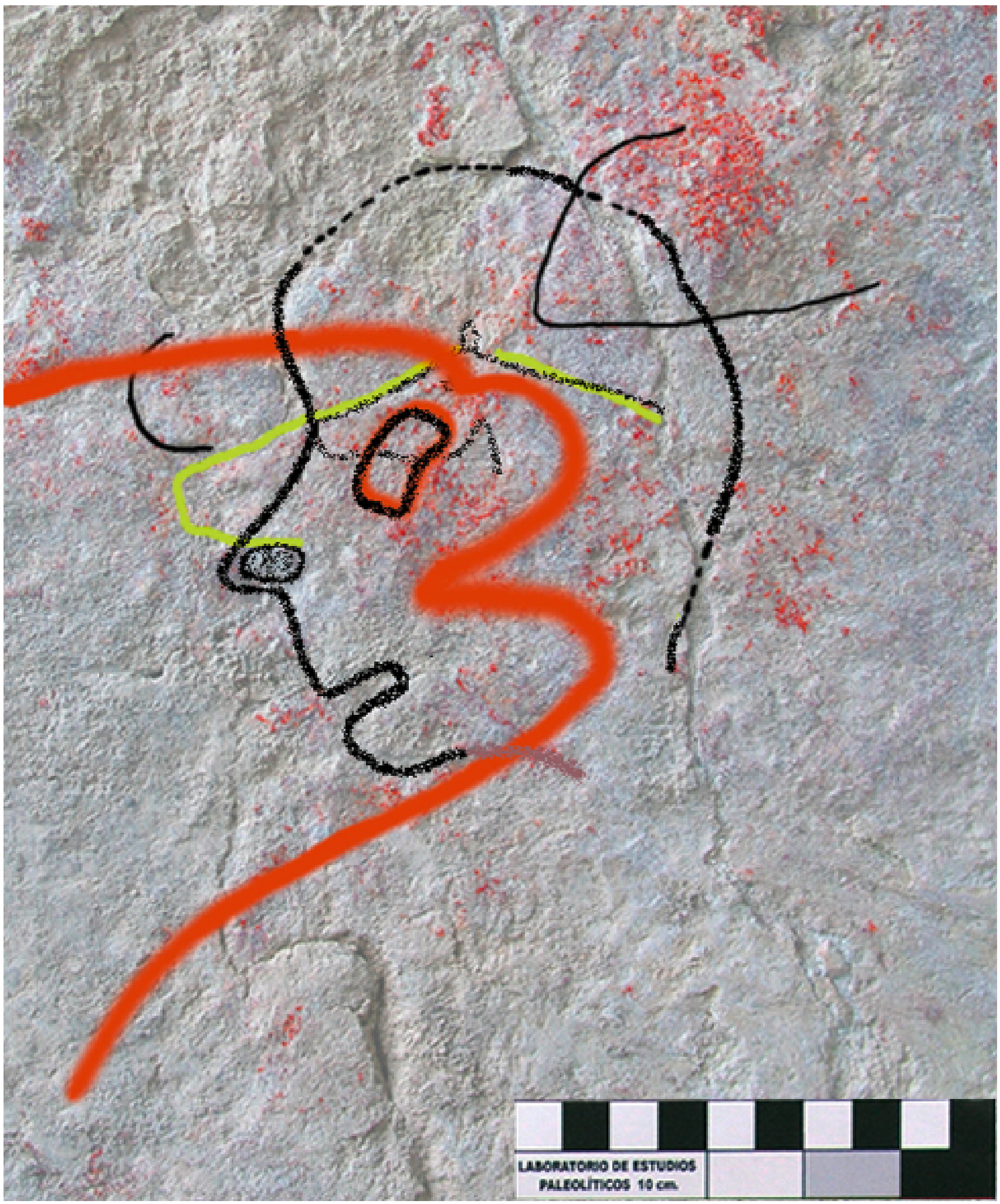

\ Figura 8. Esquema explicativo de las diferentes figuras que se superponen e infraponen al retrato humano. 
sion que enlaza con la glabela es muy pronunciada. Por otra parte está representado uno de los agujeros nasales con el contorno grabado con un trazo muy fino y somero y relleno con un pigmento negro. El perfil frontonasal adopta un aspecto ondulado teniendo el perfil cóncavo de la frente, junto con una nariz convexa ofreciendo un perfil sinuoso.

- La boca. Tras la zona situada entre el punto subnasal y los labios o zona del bigote, bastante amplia, encontramos la boca que aparece abierta y confeccionada mediante sendos trazos que en la zona interior se recurvan.

- El mentón o pogonion. En nuestra figura podría llegar a confundirse con una grieta en ángulo en la parte inferior, pero el trazo grabado profundamente parte de la boca y se recurva pronunciadamente hacia el cuello. No sobresale al plano perpendicular y además el ángulo mentocervical que mide $90^{\circ}$ está en la media general admitida para esta zona.

- El cuello. La parte de la barbilla y el inicio del cuello no están grabados como el resto de la figura, sino que aparecen pintados en ocre rojo con un trazo firme y de un grosor similar al de la incisión.

\section{Prognatismo y ortognatismo}

En antropología física el prognatismo se define mediante la medición de ángulos. Partiendo del plano horizontal aurículo orbitario de Frankfort y una línea vertical hipotética que discurre desde la parte más abultada de la frente o glabela, pasa por el surco subnasal y la mandibula, generalmente prescindiendo de la parte carnosa tanto de la nariz como de los labios. El prognatismo se sitúa en la parte externa de esta línea vertical, mientras que el ortognatismo lo hace hacia la parte interna. El retrato de La Cueva de Ambrosio es claramente ortognato. Para hablar de un auténtico retrato debe existir una individualización del personaje a partir de la imitación de los rasgos individuales, sin otro artificio. Se trata de una imagen que se compone a su vez de dos estratos relacionados: la representación de los rasgos somáticos y la búsqueda de la expresión psicológica del individuo. Hasta ahora estas caracteristicas solo aparecian a partir del Magdaleniense medio, pero este nuevo descubrimiento permite retrotraerlo al Solutrense medio.

9. Figura de una cabeza de équido dispuesta hacia la izquierda con una longitud de $25 \mathrm{~cm}$, una anchura de $7 \mathrm{~cm}$ y una máxima entre paralelas de $25 \mathrm{~cm} \mathrm{La}$ orientación es de $249^{\circ}$ y el buzamiento $72^{\circ}$. El grabado es muy fino, de sección en $\mathrm{V}$ con una anchura y profundidad inferiores a $1 \mathrm{~mm}$. Simplemente se trata de la parte superior de la silueta, con el morro, la testuz y la oreja enhiesta, a partir de la cual se inicia la línea cérvico-dorsal.

10. Pequeña cabeza de équido orientada hacia la izquierda con unas dimensiones que apenas alcanzan los $12 \mathrm{~cm}$ de longitud por $3,5 \mathrm{~cm}$ de anchura, con una orientación de $249^{\circ}$ y un buzamiento de $72^{\circ}$. La incisión es de sección en $\mathrm{V} y$ tanto la anchura como la profundidad son inferiores a $1 \mathrm{~mm}$. Al igual que la figura n. 9 dentro de la que se inscribe, carece de detalles. Únicamente se aprecia el morro, la testuz, la oreja enhiesta y el inicio del dorso. La zona de la boca se superpone al ojo arriñonado del retrato humano o del ollar del caprino n. ${ }^{\circ} 7$.

11. Triángulo vertical con el vértice en la zona derecha con una longitud de $3 \mathrm{~cm}$ y una anchura de $7 \mathrm{~cm}$. La orientación es de $240^{\circ}$ y el buzamiento de $76^{\circ}$. El grabado es muy somero tanto en profundidad como en anchura, siendo inferior a $1 \mathrm{~mm}$ y la sección es en V. La tradicional interpretación de los triángulos como esquematizaciones o como vulvas femeninas se hace muy patente en este caso por la proximidad con el retrato masculino a modo de dicotomía macho-hembra. De cualquier forma toda interpretación sexual entre ambas figuras y su significado escapan a nuestra clarividencia y comprensión.

12. Posible cabeza de équido orientada hacia la derecha (es una de las pocas que existen con esta orientación) con una longitud de $20,5 \mathrm{~cm}$ y una anchura de $16 \mathrm{~cm}$, una máxima entre paralelas de $20 \mathrm{~cm}$ Tiene una orientación de $240^{\circ}$ y un buzamiento de $76^{\circ}$. El grabado tiene una sección en $U$ y una anchura de unos $3 \mathrm{~mm}$ en la zona de la quijada y una profundidad inferior a $1 \mathrm{~mm}$. Sólo se aprecia el morro y la quijada y carece de otros detalles anatómicos que nos permitan una clasificación taxonómica más acertada.

13. Cabeza de cuadrúpedo, posiblemente un caballo orientado hacia la izquierda con una longitud de $17 \mathrm{~cm}$, una anchura de $20 \mathrm{~cm}$ y una máxima entre paralelas de $19 \mathrm{~cm}$. La orientación es de $241^{\circ}$ y el buzamiento de $76^{\circ}$. La incisión de sección en $\mathrm{V}$ abierta tiene una anchura y profundidad inferiores a $1 \mathrm{~mm}$. Simplemente se trata de una silueta de cabeza desde el arranque de la oreja (ausente por un desconchón) hasta el inicio del pecho pasando por el morro y la quijada. En el interior de esta testa se aprecia una amplia mancha de color ocre rojo bastante vivo (10R 6/6).

14. Protomos de caballo pintado en color negro orientado hacia la izquierda con $21 \mathrm{~cm}$ de longitud y 12 $\mathrm{cm}$ de anchura con una máxima entre paralelas de $21 \mathrm{~cm}$. La orientación es de $231^{\circ}$ y la inclinación 
de $80^{\circ}$. El trazo muy desvaído y baboso es de color negro-pardo (7.5 YR 5/0). El grosor del trazo varía entre 0,5 y $1 \mathrm{~cm}$ en determinadas zonas. Se trata de una figura de extraña factura ya que a pesar que se distingue con claridad un precioso caballo hito, el tratamiento digital de esta representación muestra la posible existencia de otro caballo totalmente distinto dispuesto hacia la izquierda y hacia abajo y que se localiza en la quijada-morro del antedicho équido. Por nuestra parte, teniendo en cuenta la morfología general del resto de manifestaciones de équidos en La Cueva de Ambrosio, pensamos que a falta de un ulterior análisis más exhaustivo, la figura que debe prevalecer es la grande. La oreja está incorporada a la crinera que aparece con el característico escalón, prolongándose hasta el inicio de la línea cérvico-dorsal. En el interior de la cabeza se aprecia un punto negro que sin duda por su posición corresponde al ojo. A partir de la quijada, se inicia la línea del pecho que se interrumpe. A pesar de la proximidad con el caballo $n .{ }^{\circ} 23$, la morfología de esta figura es totalmente distinta, carente de la maestría, naturalismo y realismo que presenta aquella.

15. Protomos grabado de caballo. En el ángulo superior derecho de este panel II, en una zona particularmente densa en trazos incisos, se localizan dos protomos grabados de caballos enfrentados. El de la derecha, está mucho más completo que el de la izquierda (Ripoll López et al. 1992). La figura que nos ocupa con unas medidas de $62 \mathrm{~cm}$ de longitud y $28 \mathrm{~cm}$ de anchura, con una orientación de $230^{\circ}$ y una inclinación de $75^{\circ}$. Es de una excelente factura y nos presenta un caballo robusto con una quijada "barbuda". La cabeza de forma subtriangular es muy característica de este tipo de representaciones. La testuz está realizada mediante un único trazo de sección en $\mathrm{V}$ y tiene una profundidad de 1 a 1,5 mm; se distingue una pequeña rectificación en la zona media debida a una mínima irregularidad de la roca. En el morro se puede ver claramente el ollar situado en la parte superior hecho con un trazo casi circular en cuyo interior hay otros breves surcos. El morro en sí es rectilíneo siguiendo con un trazo único y en el inicio de la quijada pierde su continuidad siendo interrumpido por un conjunto de 16 trazos más 0 menos profundos que representan las barbas. En la inflexión posterior de la mandíbula inferior se vuelve al trazo continuo, aunque en este caso la característica es que es múltiple como si el artista hubiese querido resaltar la fortaleza del animal; la quijada se prolonga hasta la parte superior del cuello uniéndose prácticamente con la línea de la crinera. No se aprecia el ojo, aunque en el interior de la cabeza existen numerosos trazos que, a falta de un estudio más profundo, creemos que se trata de despieces de la figura. En la parte superior, las dos orejas se proyectan hacia adelante en sendos trazos dobles, que adquieren una posición semejante a las del caballo pintado (n. ${ }^{\circ} 23$ ). La crinera se inicia en las orejas desdoblándose en dos trazos más o menos paralelos que se separan a medida que nos alejamos de la cabeza. La línea cérvico-dorsal se prolonga hasta la grupa y por ahora no hemos podido identificar las extremidades, por su parte la línea del pecho, en trazo múltiple, se alarga hasta el encuentro o inicio de las patas delanteras.

16. Protomos grabado de caballo. El otro caballo grabado orientado hacia la derecha con unas dimensiones de $23 \mathrm{~cm}$ de longitud por $23 \mathrm{~cm}$ de anchura, con una orientación de $230^{\circ}$ y una inclinación de $75^{\circ}$. Es de factura muy similar al que acabamos de describir, aunque quizás su aspecto en conjunto sea menos completo que el anterior pero ello es debido a la colada calcítica antes mencionada. La cabeza posee una testuz más pronunciada con un trazo simple bien marcado que se prolonga hasta el morro donde posee una inflexión. La zona del ollar se ha perdido por una pequeña fractura de la roca base y los trazos de la barba, en un número de 13, son algo más profundos en la zona de la mandíbula y a medida que se alejan de ella se hacen más finos y tenues. La quijada es menos pronunciada y penetra en un ángulo casi recto en la cabeza. En la parte alta únicamente se aprecia una oreja claramente elíptica en contraposición al resto de las representadas en las otras figuras y el inicio de la crinera no se distingue, aunque si podemos seguirla en la zona del lomo, punto éste donde de momento se pierde la representación. La línea del pecho, realizada mediante un único surco, se prolonga también hasta el encuentro. En el interior de esta figuración se identifican numerosas incisiones que se encuentran ocultas en parte por costras calcíticas.

17. Protomos de un pequeño cuadrúpedo, posiblemente una cierva, orientada hacia la izquierda con una longitud de $11,2 \mathrm{~cm}$ y una anchura de $12,2 \mathrm{~cm}$ con una orientación de $229^{\circ}$ y un buzamiento de $74^{\circ}$. El grabado es muy poco profundo y ancho ya que apenas alcanza los 0,5 $\mathrm{mm}$. $Y$ es de sección en $\mathrm{V}$. La morfología general de la cabeza, con el morro apuntado, la gran oreja y el párpado elevado, junto con el ojo almendrado, nos lleva a pensar en la posibilidad que se trate de una cierva. Tanto la línea del pecho como el inicio de la cérvico-dorsal adoptan también la morfología de este tipo de representaciones. Normalmente en las figuras de équidos, la oreja aparece enhiesta, prácticamente encima del ojo, mientras 
que en la presente, la oreja también enhiesta y con una marca interior, aparece mucho más retrasada.

18. Gran cabeza de caballo dispuesta hacia la izquierda con una longitud de $38 \mathrm{~cm}$, una anchura de $26,8 \mathrm{~cm}$ y una máxima entre paralelas de $39 \mathrm{~cm}$. Tiene una orientación de $231^{\circ}$ y una inclinación de $80^{\circ}$. Todo el contorno está grabado mediante dos técnicas distintas; por un lado la quijada aparece martilleada con un surco amplio que alcanza en algunos puntos $1,9 \mathrm{~cm}$ de anchura, aunque la profundidad es escasa. A partir del belfo, hasta la oreja, el surco es de sección en $V$ abierta con una anchura y profundidad superiores a $2 \mathrm{~mm}$. La oreja, situada en la parte superior de la cabeza aparece enhiesta y la incisión es muy somera de sección en $\mathrm{V}$. En el interior se distingue el ojo circular realizado mediante un impacto circular martilleado, siendo el único que existe en el conjunto con estas características. Es probable que haya otra cabeza de cuadrúpedo ya que en la zona del morro de esta gran testa se diferencia otro ojo circular grabado. En este panel II hemos diferenciado tres grandes cabezas, una la del caprino (n. $\left.{ }^{\circ} 7\right)$ y dos cabezas de équido ( $n .^{\circ} 18$ y n. ${ }^{\circ} 21$ ).

19. Protomos pintado de caballo dispuesto hacia la derecha con $17 \mathrm{~cm}$ de longitud, $7 \mathrm{~cm}$ de anchura y una máxima entre paralelas de $15 \mathrm{~cm}$ La orientación es de $229^{\circ}$ y el buzamiento de $86^{\circ}$. Esta cabeza de caballo pintada en ocre marrón (7.5 YR 7/4) se halla superpuesta al équido grabado n. ${ }^{0} 19$. La quijada y la testuz están bien delimitadas con un trazo de $1 \mathrm{~cm}$ de grosor, mientras que el morro que adquiere incluso la característica inflexión del belfo, está un poco más deshavído. La crinera se prolonga en un trazo de $1 \mathrm{~cm}$ de espesor hasta el inicio del dorso. Pensamos que esta figura únicamente estuvo contorneada a pesar que en su interior se distinguen algunos restos del mismo colorante, pero sin duda se deben a un corrimiento del pigmento. Se localiza a escasos $8 \mathrm{~cm}$ de la grupa del gran caballo rojo n. 23 .

20. A la derecha de este conjunto de trazos hemos podido identificar otra representación de caballo orientado hacia la derecha, realizada también con la técnica de grabado lineal muy fino (inferior a $1 \mathrm{~mm}$ ). Tanto en profundidad como en anchura y de sección en $\mathrm{V}$ ). Posee unas dimensiones de 28,7 $\mathrm{cm}$ de largo por 15,2 cm de ancho con una orientación de $230^{\circ}$ y un buzamiento de $74^{\circ}$ y creemos que está, ya que no se aprecia claramente ni los cuartos traseros ni la zona de la cabeza, sin embargo se distingue una incipiente línea del pecho. La incisión es muy somera y posee las mismas características que las descritas anteriormente. La línea ventral, en trazo múltiple, se alarga hacia la izquierda, par- tiendo desde lo que hemos considerado como la pata delantera que se ha resuelto mediante sendos trazos subparalelos, cerrándose la parte correspondiente a la pezuña con un surco perpendicular.

21. Gran cabeza de caballo hacia la derecha y abajo con una longitud de $53 \mathrm{~cm}$ desde el morro hasta la crinera y $24 \mathrm{~cm}$ de anchura desde la crinera hasta la quijada, con una orientación de $245^{\circ}$ y un buzamiento de $84^{\circ}$. Todo el contorno de la cabeza está grabado con un surco de sección en $U$ con una anchura y profundidad de $1,2 \mathrm{~cm}$. Se trata de una cabeza de caballo de grandes dimensiones, similar en tamaño a la cabeza del caprino y a la gran cabeza de caballo situada inmediatamente encima de ésta. El rasgo que mejor se diferencia es la testuz y el arranque de la oreja, así como el inicio de la crinera. También se aprecia el morro, aunque la quijada se pierde en un efracto natural. El único detalle que se aprecia en el interior de la cabeza es un ojo circular idéntico en factura al resto de las figuras de équidos de este panel II. En el interior se aprecian diversas manchas de color negro (10R $5 / 1$ ) y de color ocre rojo (10 R 6/6), como posibles restos de unas tintas planas que individualizarian este caballo por sus colores.

22. Pequeña cabeza de caballo dispuesta hacia la derecha con una longitud de apenas $8,5 \mathrm{~cm}$ y una anchura de $10 \mathrm{~cm}$ y una máxima entre paralelas de $10 \mathrm{~cm}$ La orientación es de $238^{\circ}$ y el buzamiento de $80^{\circ}$. El grabado, de sección en $\mathrm{V}$ tiene una anchura y profundidad inferiores a $1 \mathrm{~mm}$. En este caso es especialmente significativo el cambio que se ha producido en nuestra percepción de las diferentes representaciones ya que esta figura se inscribe claramente en la zona de la quijada del gran caballo $n$. $^{2} 23$. Nosotros mismos estamos sorprendidos de no haber identificado esta cabeza, teniendo en cuanta su ubicación.

23. Esta magnífica representación de équido orientado hacia la izquierda, con unas dimensiones que alcanzan los $92 \mathrm{~cm}$ de longitud por $37 \mathrm{~cm}$ de anchura desde las orejas hasta la línea del pecho y 73 $\mathrm{cm}$ de anchura desde la grupa hasta el final de la pata trasera, con una máxima entre paralelas de 92 $\mathrm{cm}$ Tiene una orientación de $235^{\circ}$ y una inclinación de $75^{\circ}$. Está pintado en ocre rojo (10R-3/3). Toda la figura esta silueteada mediante un trazo grueso que varía entre 1 y 2 centímetros de espesor en casi todo el contorno salvo la cabeza en donde oscila entre 1 y 1,5 cm Se conserva perfectamente la parte superior de la figuración, es decir la cabeza, línea del pecho, la crinera ligeramente dañada y toda la línea cérvico-dorsal hasta la grupa. En un principio pensamos que el caballo tenía el inicio de 
la cola, tal como representamos en los primeros calcos publicados (Ripoll López et al. 1992; Ripoll López 1994). En la actualidad un estudio más detallado de la figura nos ha permitido apreciar que se trata de una mayor acumulación de pigmento en la zona de la grupa. Al haber excavado durante la campaña de 1994 en esta zona, debajo del panel II, se ha mejorado notablemente la visualización de esta figura en la que se distinguen pequeños restos de pigmento que conforman lo que sería el muslo y la babilla de la pata, por otra parte muy desvaída, así como la línea curva del vientre. En la cabeza se aprecian una de las orejas y un fragmento de la otra en la parte superior hacia adelante. Así mismo la quijada con su inflexión, que sin embargo, no llega a adquirir totalmente la característica forma de "pico de pato". La línea se prolonga hasta unirse al trazo del pecho, penetrando de forma más o menos curva hacia el interior de la cabeza para marcar la mandibula. Es en esta zona, precisamente, junto con la crinera donde se aprecia una mayor concentración de colorante, e incluso se podría pensar que al pintor, al aplicar la pintura, se le corrió un poco, produciendo una ligera mancha de pigmento, sin que por el momento podamos pensar que se trata de un lavado posterior. La crinera parte de la misma altura que la oreja $y_{1} a$ pesar de existir un efracto natural de la roca, su continuidad hacia el dorso se hace patente por unos puntos pictóricos en la parte superior. Una observación de detalle de esta zona nos permite comprobar la técnica de realización de la misma. En un primer momento se silueteó con una línea exterior, rellenándose posteriormente mediante líneas de grosor variable hasta cubrir todo el espacio interior. Es en esta zona, donde la pintura está más fresca, mejor conservada y delimitada, ya que la línea cérvico-dorsal se difumina desde la crinera hacia la grupa. La línea del pecho se une a la mano por un trazo sinuoso bastante desvaido y tenue, aunque visible en una observación ocular muy próxima. Nada indica que la parte posterior de la mano y los cuartos traseros fueran jamás pintados. Es comúnmente conocido que la viveza del color, sobre todo de los óxidos de hierro, depende del grado de humedad de las paredes. La frescura de la pintura del équido del panel II de La Cueva de Ambrosio estaba en su grado óptimo, gracias a una hidrometría favorable. En esta zona -la más baja del abrigo- cuando llueve, se produce un goteo continuado. La existencia por otra parte de un nivel de arenas estériles depositado encima de un nivel de ocupación, que actúa como una capa im- permeable dado el alto contenido de materia orgánica, provoca que aquellas arenas conserven mucho la humedad, lo que sin duda ha favorecido el excelente estado de conservación de esta figura.

24. En la parte izquierda de este panel II, junto con la inferior, se distingue una amplia mancha de color negro que provisionalmente consideramos como otro équido orientado hacia la izquierda $(38 \mathrm{~cm}$ de longitud y $10,5 \mathrm{~cm}$ de anchura). Se trata de dos trazos más o menos curvos con una anchura que oscila entre 1 y 2,5 cm que configuran con bastante claridad la crinera y línea cérvico-dorsal de un caballo. El color, sin duda realizado con carbón vegetal, es muy intenso en algunos puntos (10YR 2/1), mientras que en el arranque de la cabeza se difumina poco a poco (10YR 6/1) hasta desaparecer. De esta representación tomamos una muestra que fue analizada por H. Valladas mediante AMS en el Centre des Faibles Radioactivités de Gif-Sur-Yvette (Francia), pero el análisis previo demostró que se trataba de óxido de manganeso y por lo tanto no se pudo realizar la datación radiocarbónica.

25. En la parte inferior del panel II, cubierto claramente por restos de limos fluviales de color amarillo encontramos en la campaña de 1994 un pequeño protomos de caballo $(11 \mathrm{~cm}$ de longitud y $7 \mathrm{~cm}$ de anchura) pintado en negro y rojo. A simple vista se trata de una silueta elíptica, aunque un examen en detalle de la misma nos muestra la línea de la testuz, el morro bastante desvaído y una quijada muy marcada con su correspondiente inflexión hacia el interior de la cabeza. Lo excepcional de esta figura es que la línea del pecho está realizada en ocre rojo-anaranjado (2.5YR-4/8) de escaso recorrido que junto con la cabeza negra sería un indicio de bicromía. El artista supo expresar con tres líneas una figura que claramente es un caballo. Por toda la superficie del panel II hemos descubierto numerosas manchas de ocre. Algunos restos situados a ambos lados y por encima del caballo pintado, son por el momento completamente indescifrables y no merecen más comentarios que señalar su presencia y tonalidad. Así, los que se encuentran a la izquierda del équido, es decir por delante de su cabeza, son de color marrón muy oscuro, casi negro (10YR-2/2) y rojo muy intenso (10R-4/8), mientras que los que se sitúan por detrás de la grupa son de un matiz ocre mas desvaído (10R-6/6).

Por último, en la parte superior de este panel, y por encima de la parte que se encontraba oculta por el sedimento, descubrimos otro conjunto de trazos grabados, estriados, que fueron los que nos indujeron a iniciar la limpieza de esta zona. Estas incisio- 
nes tienen una mayor complejidad identificativa ya que infrapuesta a la concreción pero rellenando el surco de los grabados, se aprecian restos pictóricos de color ocre rojo muy claro (10R-6/6). Se trata de un conjunto de trazos organizados, largos y tenues, formando haces de líneas compactas, cuya dirección es variable. Este conjunto deberá ser analizado en profundidad después de su limpieza y restauración.

\subsection{Panel III}

Durante la campaña de limpieza del año 1994, al excavar frente al panel II que en su parte más profunda coincide de forma oblicua con el fondo del abrigo, localizamos un nuevo panel con representaciones pintadas. Sobre una superficie bastante alterada de color blanquecino (5YR 8/1) se encuentran tres conjuntos pictóricos de escasa representatividad dado que se encuentran muy desvaídos, pero que sin duda engrosan el inventario provisional de figuras paleolíticas de este enclave.

1. Se trata, de izquierda a derecha de una puntuación elíptica en ocre rojo intenso (10R 3/4) con unas dimensiones de 9,8 cm de longitud por 7,5 cm de anchura. Se encuentra aislada en una superficie exenta de la pared y no tiene conexión con otras figuras.

2. En el centro del panel III muy tenue, hemos distinguido otra mancha rojiza (2.5YR 4/8) con una longitud de $15 \mathrm{~cm}$ por $14 \mathrm{~cm}$ de anchura, que aparece de forma inconexa con respecto al resto del conjunto.

3. Por último, en la zona de la derecha, se identifica una representación de mayor complejidad realizada en ocre rojo (10R 4/8) con unas dimensiones de 9,8 $\mathrm{cm}$ de longitud por $21 \mathrm{~cm}$ de anchura, que se compone de una mancha muy desvaída a la izquierda, de cuya zona inferior parte un trazo horizontal de $2 \mathrm{~cm}$ de anchura que se prolonga a lo largo de 35 $\mathrm{cm}$. En el extremo de esta línea, de nuevo hacia arriba y con una coloración muy intensa (10R 4/6) hemos diferenciado un signo rectangular cuyos lados mayores son cóncavos. La interpretación es sumamente difícil ya que se encuentra en un estado muy fragmentario y no posee una forma concreta, ni tampoco se adapta a los contornos morfológicos de alguna especie animal.

\section{ENCUADRE CRONOLÓGICO}

Raras son las estaciones en las que se encuentran representaciones parietales cubiertas por niveles arqueológi- cos que permiten datarlos con precisión, y éste es el caso de La Cueva de Ambrosio. Si bien el panel I actualmente está a la intemperie, en su momento estuvo cubierto por los niveles intactos que se encuentran a escasos centímetros hacia la izquierda y que fueron removidos por excavadores incontrolados así como por el natural desmoronamiento de los cortes de la trinchera abierta por E. Ripoll Perelló en los años 60. Hasta el momento no hemos podido constatar el suelo de habitación desde el cual se debieron de realizar estas figuras, pero sin duda, por su posición relativa, debió de ser desde el nivel IV, encuadrado en el Solutrense superior. A continuación describiremos brevemente de techo a base, la secuencia estratigráfica establecida por nosotros en esta zona, que nos permite encuadrar cada una de las representaciones en un horizonte cultural concreto (Fig. 14).

En esta zona del abrigo, se encuentra, en primer lugar, un nivel de sedimento revuelto de escasa potencia $(38 \mathrm{~cm})$ que posee abundante material arqueológico, conteniendo seguramente los restos de los niveles postpaleolíticos que ya se habian constatado en los proyectos anteriores. A continuación aparece un potente nivel $(78 \mathrm{~cm})$, al parecer, Epipaleolítico -aunque de escasa extensión- excavado ampliamente en los años 60 por E. Ripoll $(1960,1961 / 62)$ y en 1975 por M. Botella y cuyo material fue estudiado posteriormente por $A$. Suárez (1981). Este horizonte cultural se conservaba presumiblemente sólo en esta zona del abrigo, habiendo desaparecido en el resto. El material aparece entre grandes bloques de piedras y el sedimento es muy suelto y polvoriento lo que en ocasiones le confiere un cierto aspecto de estar removido.

Debajo, sin una aparente discontinuidad, salvo por un ligero cambio de coloración del sedimento, se presenta el nivel I de color amarillento, que es estéril, sin industria lítica, pero con algunos restos faunisticos de colonias naturales, fundamentalmente microfauna, lagomorfos y aves. Este estrato tiene un espesor de casi un metro $(93 \mathrm{~cm})$ y posee gran cantidad de cantos angulosos procedentes de desprendimientos de la visera que además están muy lavados debido a un alto grado de pluviosidad (Jordá Pardo y Carral 1988). Así mismo el nivel I de esta zona se paraleliza perfectamente con nuestro también nivel I encontrado en el centro del abrigo (Ripoll López et al. 1988)

En la secuencia estratigráfica que estamos describiendo, seguidamente se encuentra el nivel II, encuadrado en el Solutrense superior evolucionado, que en esta zona tiene poco espesor (oscila entre 12 y $18 \mathrm{~cm}$ ). Este nivel más reciente del Solutrense en La Cueva de Ambrosio poseía una datación radiocarbónica convencional de $16500 \pm 280 \mathrm{BP}$ y una composición industrial del grupo solutrense con algunas hojas de laurel, abundantes puntas de aletas y pedúnculo y puntas de muesca de retoque abrupto y ausencia total de puntas de cara plana. El componente de hojitas de dorso adquiere una gran representatividad al igual que el de los buriles que casi siempre son diedros de ángulo (Ripoll López et al. 1988). 
Hace unos años realizamos una serie de nuevas dataciones con el fin de comprobar la secuencia cronológica de los distintos horizontes culturales. Para este nivel II contamos con tres fechas realizadas tanto por $\mathrm{C} 14$ convencional como por AMS. Las fechas arrojan una antigüedad de $19250 \pm 70$ BP (GIF 9883), $19950 \pm 210$ BP (GIFA 95577) y $20150 \pm 200$ BP (GIFA 95577). Como podemos observar, las nuevas dataciones han envejecido este nivel del Solutrense final en unos 3000 años, pero las fechas obtenidas están mucho más de acuerdo con las dataciones que conocemos de otras estaciones peninsulares, fundamentalmente portuguesas, datadas recientemente.

El nivel III, también estéril y de color amarillento, vuelve a tener las mismas caracteristicas que las descritas en el nivel I. Hay que destacar la existencia de algunos restos de talla, procedentes sin duda de la filtración del nivel superpuesto. En esta zona podemos diferenciar la parte superior con mayor número de cantos angulosos y la parte inferior compuesta por arenas. En la zona central del abrigo que nosotros hemos excavado, alcanza este estrato una potencia de $85 \mathrm{~cm}$ En la parte oeste del abrigo, hemos llegado hasta la base del nivel, con una potencia de $70 \mathrm{~cm}$, que se asemeja mucho a la excavada anteriormente. Este nivel estéril (III) en la parte interior del abrigo, donde se sitúa el panel II, se convierte en una acumulación de arenas de transporte fluvial que en parte todavía cubre la representación pintada de la cabeza de caballo negra ( $\left.n .^{\circ} 24\right)$.

Inmediatamente debajo de esta capa se encuentra un paquete sedimentario mucho más húmedo de lo que normalmente aparece en esta estación y que encuadramos con toda seguridad en el Solutrense superior ya que se correspondería con el nivel IV excavado, datado anteriormente por radiocarbono convencional en $16620 \pm 280 \mathrm{BP}$. El conjunto industrial solutrense de este nivel está compuesto por numerosas hojas de laurel, algunas puntas de cara plana, algunas puntas de muesca de retoque abrupto y de forma esporádica aparecen puntas de aletas y pedúnculo. Son muy raras las hojas de sauce y el grupo de las hojitas y los buriles pierden representatividad con respecto a la descripción que hemos hecho para el nivel II. Para este nivel actualmente contamos también con una nueva fecha $\mathrm{C} 14$ que lo sitúa en $21520 \pm 120$ BP (GIF 9884). Desde este horizonte ocupacional se realizaron tanto las representaciones del panel I como las del panel II y las del panel III.

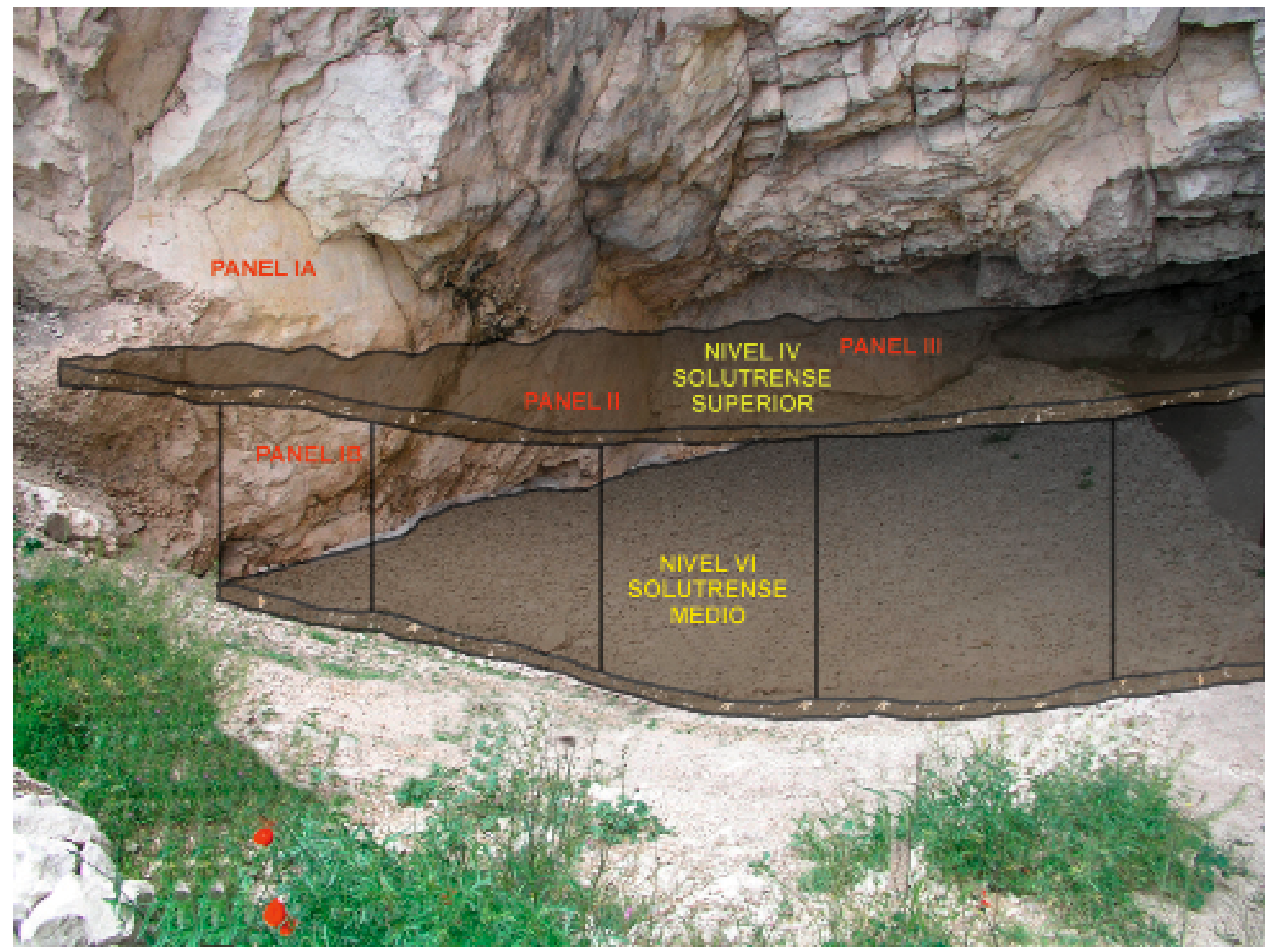

A Figura 14. Esquema explicativo de la posición que ocupaban los distintos niveles antes de las labores de excavación. 
El nivel $V$ se corresponde con la parte superior del infrapuesto nivel VII, pero al estar el nivel VI acuñado y debido al buzamiento de todos los niveles, no se advirtió que este nivel era complementario del inferior. La matriz es la misma, de arcilla bastante suelta, de color amarillo-verdoso, con gran cantidad de cantos angulosos de pequeño y mediano tamaño. Este nivel se excavó en el año 1983, y al aparecer entre dos niveles de hogares, no pudimos pensar que se trataba del mismo estrato que aparecía debajo del nivel VI de hogares. En el año 1986 comprobamos que, debido al acuñamiento del nivel VI, los niveles $\mathrm{V}$ y VIla se unían formado un sólo estrato, con una ligera diferencia en la base debido al cono de arcillas muy compactas.

El nivel VI de hogares estaba acuñado, desapareciendo casi por completo en la zona sur. La parte central de este hogar aparece en la zona norte y su potencia en este punto varía entre 10 y $15 \mathrm{~cm}$, mientras que en los extremos, oscila entre 3 y $5 \mathrm{~cm}$. La matriz sigue siendo arcillosa, pero más seca y mucho menos compacta. En la parte central del hogar, la concentración de carbones y cenizas, es tal, que la tierra se tiñe totalmente de negro, mientras que en los bordes cambia hacia marrón oscuro. En este nivel aparecen pocas piedras, y ninguna de ellas forma algún tipo de estructura que delimite la zona de hogares. La ocupación antrópica queda atestiguada por la gran cantidad de restos, tanto líticos como de fauna, hallados dispersos por toda la zona excavada, no habiéndose observado ninguna zona determinada para la talla o bien para el despiece de animales. Sin embargo hay una mayor concentración de restos en la parte central del hogar. El que no se encuentre una zona con mucha fauna, nos podría hacer pensar en un despiece selectivo de las diferentes partes del cuerpo, bien dentro del abrigo, o fuera de él. Esta hipótesis ya planteada en otros yacimientos no puede ser afirmada totalmente, ni tampoco negada, hasta que no se haya excavado la totalidad de la superficie de la cueva. Para este nivel contábamos con una fecha convencional de $17000 \mathrm{BP}$, pero a falta de una nueva datación y vistas las que actualmente poseemos para los niveles situados por encima, pensamos que tiene que ser mucho más antiguo. En un futuro próximo esperamos poder obtener nuevas fechas que corroboren nuestra hipótesis.

Todos estos niveles hasta aquí descritos, que juntos tienen una potencia de 4,97 metros, serían los que cubririan todas las superficies decoradas. El panel I-A en su parte superior estaría cubierto por los niveles finipleistocenos, así como por los estratos I (estéril), II Solutrense superior evolucionado con una datación actualizada que oscila entre 19250 y 20150 BP y III (Estéril), habiéndose realizado desde el suelo de ocupación correspondiente al nivel IV, es decir Solutrense superior, con una nueva datación de $21520 \pm 120 \mathrm{BP}$

Por otra parte los paneles I-B, II y III, que tienen una posición mucho más baja con respecto al anteriormente descrito, estarían cubiertos por el nivel IV, Solutrense superior, el nivel $V$ (estéril y se habrian realizado desde el horizonte cultural Solutrense medio que tiene que ser sin duda mucho más antiguo que el nivel antrópico antes descrito.

Además de una posición cronológica perfectamente establecida por los niveles arqueológicos que como hemos visto cubrian estas representaciones, estilisticamente su adscripción cultural es muy próxima ya que casi todas ellas se incluirian en el estilo III de A. Leroi-Gourhan (1965). Los motivos que nos llevan a clasificarlas dentro de este apartado es que la línea cérvico-dorsal de las figuras tiende a desvanecerse haciéndose muy tenue en el caso de la pintura y perdiéndose casi totalmente en el caso del grabado. La naturalidad que tienen todas las representaciones, alejándose de los elementos estereotipados que caracterizan al estilo II, así como algunas de las líneas de despiece de las crines de los équidos, junto con la ya mencionada desaparición de la curva cérvico-dorsal, nos hacen pensar que nos encontramos en un momento avanzado del estilo III propuesto por Leroi-Gourhan (1965). Así mismo los caballos barbados cuyo paralelismo con los hallados en la cueva de Les Combarelles (Eyzies, Francia) (Barrière 1985) y cuyo encuadre solutrense ya fue asignado en su dia, redunda en la idea de que estas representaciones se tienen que adscribir necesariamente a este período. De cualquier forma, si aceptamos la subdivisión estilística de este investigador francés, las representaciones de La Cueva de Ambrosio habría que situarlas en un momento final del Solutrense o tal vez en el inicio del Magdaleniense. Como ya hemos expuesto en otros trabajos este momento final del Solutrense se correspondería con el Solutrense superior mientras que el Solutrense superior evolucionado sustituiría en esta zona levantina al Magdaleniense Inferior y medio (Ripoll López 1988).

\section{CONVENCIONES CRONOESTILÍSTICAS Y SÍNTESIS ICONOGRÁFICA}

Sin duda al analizar las representaciones prehistóricas podemos pensar que hay algo más y que los artistas no plasmaron este repertorio de figuras simplemente para sentirse fuertes frente a las especies que iban a cazar, o bien como una simple zooteca. Pensamos que la constatación de la existencia de arte rupestre paleolítico en estaciones de carácter no permanente como La Cueva de Ambrosio, obliga a revisar las líneas de investigación seguidas hasta ahora y a contemplar el fenómeno artístico paleolítico en un contexto amplio que comprenda el marco geográfico regional y socioeconómico de las sociedades que lo desarrollaron. Sólo así pueden surgir nuevos planteamientos y cuestiones de interés en torno al siempre resbaladizo tema de la comprensión del arte paleolítico o su porqué. Aun así nosotros no queremos abordar de momento esta ardua cuestión de la interpretación, que creemos esconde un motivo intrínseco, 
aunque indescifrable para nosotros, en su realización. También pensamos que este delicado campo de la investigación sobre el papel que jugó el arte prehistórico, es limitado y la mayor parte nos es absolutamente desconocido y por ello las especulaciones interpretativas suelen llevar a resultados excesivamente simplistas. Es por todo ello que por ahora nos limitaremos a constatar que en las paredes del abrigo de La Cueva de Ambrosio existe una serie de figuras, fundamentalmente équidos, grabados y pintados.

En cuanto a la posible interpretación del conjunto pictórico de La Cueva de Ambrosio, podríamos caer en las ya manidas teorías de la magia propuestas por Salomón Reinach o Begouen y la del arte por el arte seguida fundamentalmente por Boule, entre otras. Sin embargo la mayoría de los autores contemporáneos prefieren conjugar ambas teorías. Esta diversidad de interpretaciones se corresponde con una realidad sumamente compleja y sería vano el buscar explicaciones de carácter general para una justa y correcta explicación del arte paleolítico.

En una región donde las manifestaciones pictóricas paleolíticas son muy escasas, cuando no ausentes, estas representaciones son sorprendentemente clásicas. La Cueva de Ambrosio es una de las pocas estaciones con arte rupestre parietal de la Península lbérica datada de una manera absoluta, que además posee la característica de hallarse en la zona mediterránea, donde casi siempre se hace referencia a la colección de plaquetas de la cueva del Parpalló (Gandía, Valencia) (Pericot García 1942; Villaverde Bonilla 1994), así como de encontrarse las figuras al aire libre al tratarse de un abrigo y no en la profundidad de una cueva desprovistas de iluminación natural. Estas figuras parietales además de ofrecer un gran interés por su importancia y calidad artística, ciertamente superior a las que normalmente se presentan en los escasos conjuntos de arte rupestre paleolítico de la región mediterránea, lo tienen por su situación geográfica en el Sureste español. El descubrimiento de estas figuraciones viene a llenar el vacío que existía en esta zona en la dispersión geográfica del arte parietal cuaternario de la Península Ibérica, únicamente representado por el équido martilleado de estilo paleolítico de Piedras Blancas (Escullar, Almería) (Martínez 1986/87). Como ya hemos explicado en numerosas ocasiones, la Cueva de Ambrosio se encuentra situada en la cabecera del valle del arroyo del Moral siendo su posición geográfica de gran importancia ya que constituye el centro de una encrucijada de vías naturales para acceder desde el Levante mediterráneo al interior de Andalucía. Esta zona montañosa está limitada al Norte por los extensos Ilanos que unen Caravaca de la Cruz, en la provincia de Murcia con La Puebla de Don Fadrique, Huescar y Baza ya en la provincia de Granada, donde se encuentra con la otra vía sureña de penetración. Se trata de las Ramblas de Nogalte y de Chirivel que unen Puerto Lumbreras, también en Murcia, con la población antes citada (Baza). La situación privilegiada en esta zona pudo contribuir a la difusión y sintesis de determinados tratamientos estéticos, estilísticos y temáticos, ya sea desde la Andalucia continental hacia el Levante o bien al contrario.

Hay que señalar que, cuando se pueda retirar totalmente los depósitos de piedra y sedimento intacto que cubrian, y en parte todavía cubren parte de estos paneles de la cueva, seguramente aparecerán nuevas figuras que engrosarán el inventario. En esta zona, donde hemos documentado el sondeo realizado por el profesor Eduardo Ripoll en el año 1963, también hemos comprobado que el nivel VI está prácticamente intacto y la superficie rocosa correspondiente al panel II, sigue hacia abajo. Es de suponer que en el momento que se realice la excavación sistemática de esta zona, seguirán apareciendo representaciones parietales..

En Europa únicamente existen cuatro yacimientos paleolíticos que posean las características de posibilidad de datación absoluta por estar cubiertas las representaciones por niveles arqueológicos y se trata de la cueva de La Viña (Asturias), donde se encontraron algunas representaciones naturalistas cubiertas por niveles encuadrados en el Magdaleniense medio cantábrico evolucionado (Fortea 1981 y 1990). En el año 2001 apareció la noticia (Beltrán 2002) del hallazgo de diversas representaciones parietales en la Cova del Parpalló (Gandía, Valencia). Aunque en la actualidad estas figuras están a gran altura, respecto al suelo actual, en su momento estuvieron recubiertas por los niveles arqueológicos que excavó el profesor L. Pericot en los años 30 (Pericot 1942) se trata de un équido, un caprino y varias líneas inconexas así como un cuadrúpedo pintado en ocre rojo que están situados por encima del lugar en el que se ubicaba el nivel Solutrense medio y superior de Pericot. En la cueva de El Mirón (Ramales de la Victoria, Cantabria) también se han encontrado algunas representaciones no figurativas cubiertas por los niveles arqueológicos que las encuadran en un Magdaleniense medio cantábrico /García Díez, Strauss y González Morales 2012). En la grotte de La Tête du Lion en Francia, (Ardèche, Francia) (Combier 1972 y 1977) en la que las representaciones pictóricas no estaban propiamente cubiertas por los estratos, pero la excavación sistemática realizada en la base de las pinturas, proporcionó los útiles, "lápices" y carbones utilizados para su realización, que permitieron datarlas. A partir de ahora habrá que añadir el conjunto de figuraciones halladas en La Cueva de Ambrosio.

Los frecuentes descubrimientos de estaciones con arte prehistórico al aire libre o en yacimientos, como puede ser el caso que nos ocupa, sin duda introducirán numerosos e importantes cambios en las ideas generalmente admitidas referentes a la distribución geográfica, tanto del arte paleolítico como del Ilamado arte postpaleolítico. Los esquemas impuestos por grandes investigadores han provocado que estas zonas fueran tenidas como excepciones que contradecían objetivamente los pragmatismos al uso, de cómodo manejo y que incorporaban marginalmente, a lo sumo, a 
sucesivas puestas al día que, al poco tiempo, quedaban a su vez anticuadas al no modificar la base de los problemas, limitándose a aceptar supuestos anómalos que al multiplicarse, nos obligan a realizar una revisión de estos problemas, hasta ahora admitidos como indiscutibles. Estas cuestiones deberán de ser abordadas en profundidad en reuniones científicas específicas que aporten alguna luz a la distribución y datación del arte rupestre paleolítico peninsular. •

\section{BIBLIOGRAFÍA}

ALTUNA, J. 1983: "On the relationship between archaeofaunas and parietal art in the caves of the Cantabrian Region". En J. Clutton-Brock y C. Grigson (eds.): Animals and Archaeology 1. Hunters and their prey. BAR International Series 163. Londres: 227-238.

ARCHAMBEAU, M. 1984: Les figurations humaines pariétales perigourdines. Étude d'un cas: Les Combarelles. Thèse de Doctorat de 3e cycle. Université de Provence.

BARRIERE, C. 1985: La grotte des Combarelles I. Relevés des gravures de la galerie profonde. Travaux de I'Institut d'Art Préhistorique XXVII. Université de Toulouse-Le Mirail.

Beltrán Martinez, A. 2002: "Art rupestre dans la grotte du Parpalló (Gandia, Valence, Espagne). International Newsletter on Rock Art". Bulletin de I'I.N.O.R.A. 33: 7-11.

BosINSKI, G. 1981: Gönnersdorf. Eiszeitjäger am Mittelrhein. Selbverlag des Lasdesmuseums Koblenz.

BosINSKI, G. y FISCHER, G. 1974: Die Menschendarstellungen von Gönnersdorf der Ausgrabung 1968. Steiner Franz Verlag. Wiesbaden.

CACHO, C. y Ripoll López, S. 1987: "Nuevas piezas de arte mueble en el Mediterráneo español". Trabajos de Prehistoria 44: 35-62.

Combier, J. 1972: "La Grotte de la Tête du Lion à Bidon (Ardèche)". Etudes Préhistoriques 3: 1-11.

- 1977: Dix ans de recherches préhistoriques dans la région RhôneAlpes (1965-1975)". Gallia Préhistoire 20 (2): 576-578.

DELPORTE, H. 1979: L'image de la femme dans l'art préhistorique. Editions Picard. Paris (traducción al castellano de J. M. Tabanera, Madrid, Editorial Itsmo, 1982).

DuRAD, J. P. 1996: Réalisme de l'image masculine paléolithique. Collection L'Homme des Origins. Editions Jérome Million.

EICKSTED VON, E. 1952: Menschen und Menschendarstellungen der Steinzeitlichen Hölenkunst in Frankreich und Spanien. Sonderdruckzeitschrift für Morphologie und Anthropologie XLIV (1-3).

FoRTEA, F. J. 1981: "Investigaciones en la Cuenca Media del Nalón. Asturias (España)". Zephyrvs XXXII-XXXIII: 5-16.

Fortea, J., CORChÓN, M. S. y González Morales, M. R 1990: Travaux récents dans les vallées du Nalón et du Sella (Asturies). Colloque International L'art des objets au Paléolithique. I, L'art mobilier et son contexte. Foix-Le Mas d'Azil 1987. Paris: 219-244.

Garcia Díez, M., González Morales, M. R. y Strauss, L. G. 2012: "El grafismo rupestre paleolítico de la cueva de El Mirón (Ramales de la Victoria, Cantabria, España): una propuesta para su datación estratigráfica". Trabajos de Prehistoria 69 (1): 21-36.

Jordá PARdo, J. y CARRAL, M. P. 1988: "Geología y estratigrafía del yacimiento prehistórico de la cueva de Ambrosio (VélezBlanco Almeria)". En S. Ripoll López (ed.): La Cueva de Ambrosio (Vélez-Blanco, Almería) y su posición cronoestratigráfica en el Mediterráneo Occidental. BAR International Series 462. 0xford: 19-40.

Lerol-Gourhan, A. 1965: La Préhistoire de l'art occidental. Edit. Mazenod. Paris.

Martinez Garcí, J. 1986/1987: "Un grabado paleolítico al aire libre en Piedras Blancas (Escullar, Almeria)". Ars Praehistorica V/VI: 49-58.

MunselL, A. H. 1954: Munsell soil color charts. Munsell Company Inc. Baltimore.

Pales, L. y Tassin de Saint Péreuse, M. 1976: Les gravures de La Marche. II- Les humains. Editions Ophrys.
Pericot Garcia, L. 1942: La cueva del Parpalló (Gandía). Instituto Diego Velázquez. Consejo Superior de Investigaciones Cientificas. Madrid.

Powell, N. y HumphreYs, B. 1984: Proportions of the Aesthetic Face. Thieme-Stration. New York.

Ripoll López, S. (ed.) 1988: La Cueva de Ambrosio (Vélez-Blanco, Almería) y su posición cronoestratigráfica en el Mediterráneo Occidental. BAR International Series 462. Oxford.

- 1989: "Le gisement de La Cueva de Ambrosio: Nouveaux Apports au Solutréen de la Péninsule Ibérique". L'Anthropologie 92 (4): 851-886.

- 1990: "Le Solutréen dans le Sud de la Péninsule Ibérique". Colloque International sur Les industries á pointes foliacées du Paléolithique Supérieur européen. ERAUL 42. Liège: 449-465.

- 1993: "Estudio cultural, reconstrucción paleoecológica y posición cronoestratigráfica del Pleistoceno Superior Final en la Andalucía Oriental. La Cueva de Ambrosio (Vélez-Blanco, Almería)". Investigaciones Arqueológicas en Andalucía: Proyectos: 239-251.

- 1994: "L'art rupestre paléolithique de La Cueva de Ambrosio (Almería, Espagne)". International Newsletter on Rock Art. Bulletin de I'I.N.O.R.A. 7: 1-2.

Ripoll López, S. y CACHO, C. 1990: Art mobilier du Paléolithique mediterranéen espagnol: quelques nouvelles découvertes. Colloque International L'art des objets au Paléolithique, Foix-Le Mas d'Azil, Noviembre de 1987. Ministère de la Culture. Foix: 287-293.

Ripoll lópez, S., Muñoz, F. J., Ascasibar, J., Calleja, F. y Gomis, E. 1992: "Descubrimiento de grabados y pinturas en el yacimiento solutrense de La Cueva de Ambrosio (Vélez-Blanco, Almeria)". Primer Congrés Internacional de gravats rupestres y murals, Lleida 23-27 de noviembre de 1992: 155-169.

Ripoll López, S., Muñoz Ibáñez, F. J. y Latova Fernández LunA, J. 2006: "Nuevos datos para el arte rupestre paleolítico de La Cueva de Ambrosio (Vélez Blanco, Almeria)". Congreso de arte esquemático en la Península lbérica. Vélez-Rubio y Vélez-Blanco, Almería 5-7 de mayo de 2004: 547- 562.

Ripoll lópez, S., Muñoz, F. J., Pérez, S., MuÑiz, M., Calleja, F., Martos, J. A. y AMAYA, C. 1994: "Arte rupestre paleolítico en el yacimiento solutrense de La Cueva de Ambrosio (Vélez-Blanco, Almería)". Trabajos de Prehistoria 51: 21-39.

Ripoll lópez, S., Pérez, S., López, R., Paniagua, J. P., Muñoz, F. J., Muñiz, M., Calleja, F. y martos, J. A. 1995: "Art parietal paléolithique de la Grotte d'Ambrosio (Almeria, Espagne)". Bulletin de la Société Préhistorique Ariège-Pyrénées L: 97-116.

Saccasyn della Santa, E. 1947: Les figures humaines du Paléolithique Supérieur Euroasiatique. Ed. Sikkel. Antwerp.

SACCHI, D. 2008: "Un thème de l'iconographie magdalénienne: le bouquetin dardant la langue". Espacio, Tiempo y Forma. Serie I Prehistoria y Arqueología, nueva época 1: 93-104.

Sánchez Marco, A. 1988: La Avifauna de La Cueva de Ambrosio. En S. Ripoll López (ed.): La Cueva de Ambrosio (Vélez-Blanco, Almería) y su posición cronoestratigráfica en el Mediterráneo Occidental. BAR International Series 462. 0xford: 143-156.

SuÁrez Márouez, A. 1981: "Cueva de Ambrosio (Vélez-Blanco, Almería). Nuevas aportaciones al estudio del Epipaleolítico del Sudeste Peninsular". Arqueología y Paleoecología Humana 2: 43-53.

VIALOU, D. 1981: "La figuration humaine au Paléolithique Supérieur". En D. Ferembach (dir.): Le processus de I'hominisation. L'evolution humaine. Les faits. Les modalités. Colloques Internationaux du Centre National de la Recherche Scientifique. Paris: 133-139. 
EL ARTE RUPESTRE PALEOLítICO DE LA CUEVA DE AMBROSIO (VÉLEZ-BLANCO, ALMERÍA, ESPAÑA). UNA VISIÓN VEINTE AÑOS DESPUÉS

Villaverde Bonilla, V. 1994: Arte Paleolítico de la Cova del Parpalló. Estudio de la colección de plaquetas y cantos grabados y pintados. Servei de Investigació Prehistòrica. Diputació de València. València.
WatKINS, P. y LUBIT, E. 1992: "Profile changes in the now - growing black patients following extractions mechano therapy". Am. Journal of orthodontics and dento facial orthopaedics 102 (1): 95. 
